\title{
A LA SOMBRA DEL ARSENAL: LA OFERTA EMPRESARIAL FERROLANA EN EL SIGLO XIX
}

\author{
ELVIRA LINDOSO TATO \\ Universidade de A Coruña
}

\begin{abstract}
Resumen
La mayor parte de los estudios sobre la economía ferrolana en el siglo XIX se centran en su industria emblemática, el sector naval. El principal objetivo de este trabajo es el estudio del sector privado empresarial en la ciudad y su área de influencia durante el siglo XIX. Sociedades e inversión de capital son los instrumentos usados en la investigación de la oferta empresarial. Además, el trabajo investiga los enlaces entre el ritmo del desarrollo económico del área y la evolución de la construcción naval pública.
\end{abstract}

\section{Palabras clave}

Galicia, Ferrol, Siglo XIX, Historia empresarial, Comercio, Industria.

\begin{abstract}
Most of the studies about the economy of Ferrol in the $19^{\text {th }}$ century focuses on its main industry, the naval sector. The first aim of this paper is the study of the whole private business sector in the city and its hinterland during the nineteenth century. Companies and capital investments are the instruments used in the research on the business supply. Besides, the work investigates the links between the rhythm of the economic development in the area and the evolution of the public shipbuilding.
\end{abstract}

\section{Key Words}

Galicia, Ferrol, XIX century, Business History, Trade, Industry. 
Gran parte de la historiografía sobre la evolución económica de Ferrol en el siglo XIX se ha centrado en lo que, durante muchos años, ha sido la industria emblemática de la urbe, la construcción naval, dejando de lado el resto de iniciativas que la ciudad pudo haber acogido o tratándolas de forma marginal ${ }^{1}$. En los últimos años han aparecido varias publicaciones acerca de Ferrol y su comarca que han arrojado alguna luz sobre el desarrollo de otros sectores distintos al naval ${ }^{2}$. En cualquier caso, la mayor parte de los autores han coincidido en señalar la gran influencia que el Arsenal ferrolano seguía teniendo sobre la comarca. En general, Ferrol se nos ha presentado habitualmente como una ciudad demasiado marcada por los vaivenes de los presupuestos públicos y su impacto en la construcción naval, tanto desde el punto de vista económico como demográfico ${ }^{3}$. Cardesín (2004: 329-356) ha señalado que los programas navales de los reinados de Fernando VI y Carlos III junto con la expansión del comercio colonial explicaron la expansión ferrolana de la segunda mitad del Setecientos. En el siglo XIX, la dependencia de la política naval continuó siendo esencial para explicar las fases de auge y decadencia en la ciudad.

En consecuencia, uno de los objetivos planteados en este trabajo ha sido la identificación de los ritmos económicos seguidos por el Ferrol del Ochocientos, confrontando su trayectoria con la seguida por los núcleos gallegos más dinámicos del siglo XIX, A Coruña, Vigo y Santiago. Asimismo, pondremos de manifiesto la oferta empresarial existente en la ciudad al margen del Arsenal. Con estas premisas, hemos construido una serie de compañías mercantiles fundadas en la ciudad de Ferrol desde la década de los veinte del siglo XIX hasta comienzos del siglo XX, resultado de la combinación de los registros mercantiles y los protocolos notariales del distrito ferrolano ${ }^{4}$. El ritmo de constitución de las sociedades, los capitales invertidos y las actividades que realizan serán indicativas tanto de las expectativas de inversión que se generaron en la ciudad como del ciclo económico mantenido durante el siglo XIX.

\footnotetext{
${ }^{1}$ La diversa bibliografía dedicada al estudio del Arsenal ferrolano desde su fundación en el siglo XVIII hasta mediados del siglo XIX podemos encontrarla recogida en Lozano (1997: 23).

${ }^{2}$ Véanse, por ejemplo, las publicaciones de revistas especializadas tales como Ferrol Análisis y Revista de Neda, que han contribuido a revitalizar los estudios sobre la comarca ferrolana.

3 Lozano (1997: 27-44).

${ }^{4}$ La información proporcionada por el Registro Mercantil y los protocolos notariales ha sido un recurso bastante socorrido a la hora de reconstruir el marco empresarial de un territorio. Lindoso (1999, 2003 y 2005) efectúa un repaso a la historiografía y a la metodología aplicada en la construcción de las series de sociedades mercantiles al que remitimos al lector con el fin de no sobrecargar el texto.
} 


\section{UN CONTRASTE URBANO A LARGO PLAZO}

Las tres metrópolis gallegas por excelencia durante la mayor parte del siglo XIX fueron Ferrol, Santiago y A Coruña. Estas tres ciudades concentraron la mayor parte de las iniciativas empresariales del siglo XIX, sumándoseles Vigo a finales de la centuria ${ }^{5}$. Las cuatro urbes, radicadas en las provincias más litorales, fueron las principales beneficiarias de la movilidad espacial interior de la población gallega durante el XIX'.

\section{Gráfico 1}

La población de las principales ciudades gallegas, 1787-1920

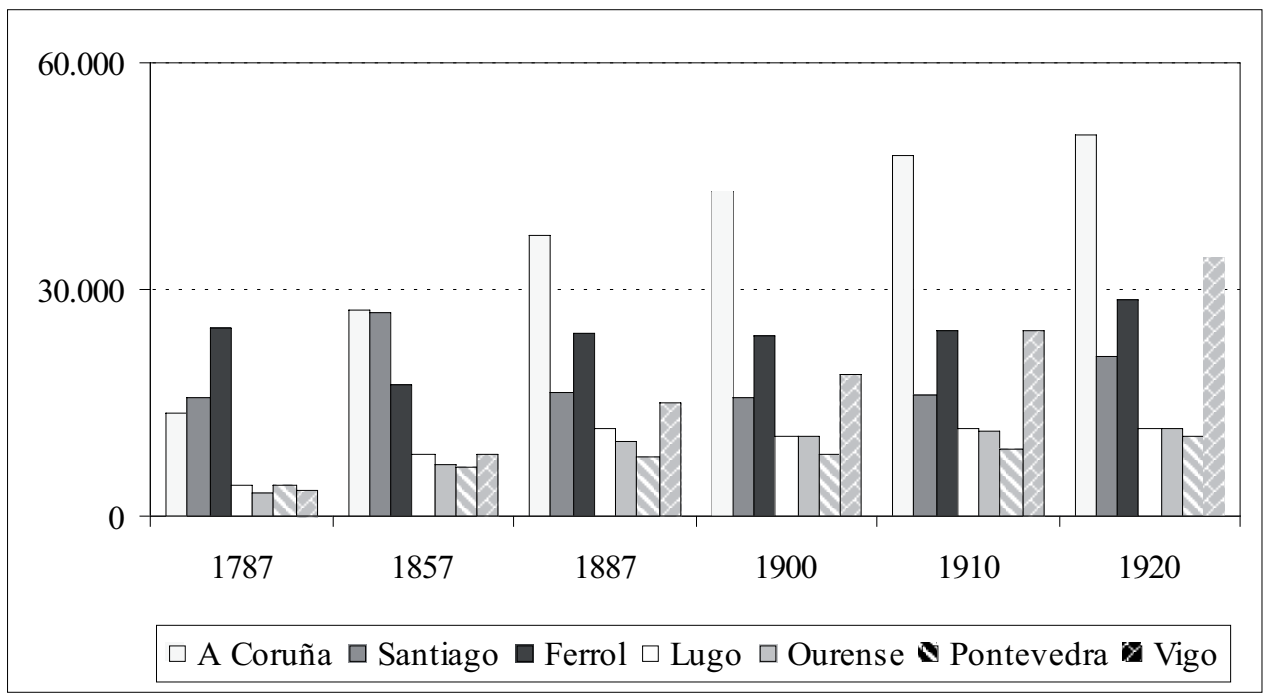

Fuentes: López Taboada (1996: 39-62, 284-287), Eiras Roel (1988: 156).

A finales del siglo XVIII, Ferrol se había convertido en la ciudad gallega más poblada gracias, sobre todo, a la atracción que ejercían los trabajos del Arsenal. Pero esta situación cambió en la primera mitad del siglo XIX, cuando la actividad del establecimiento decayó fuertemente. Ferrol experimentó fuertes pérdidas demográficas en la primera mitad del siglo XIX. En 1787 acogía casi a 25.000 habitantes y

${ }^{5}$ Vigo, al iniciarse la Restauración, era todavía una población de menor entidad que vivía de la pesca y la salazón, véase Álvarez Blázquez (1980).

${ }^{6}$ Barreiro Gil (1990: 14). 
setenta años después había perdido la tercera parte de la población (gráfico 1).

El crecimiento ferrolano del siglo XVIII estuvo asociado a la puesta en marcha del Arsenal. Su población y su economía se movían en torno al Arsenal. La segunda mitad del Setecientos fue una etapa expansiva para Ferrol tanto desde el punto de vista demográfico como económico al ir acompañada de una actividad constructora intensa en los astilleros. Sin embargo, la dependencia de los fondos públicos era su talón de Aquiles ${ }^{7}$. En los últimos años del Antiguo Régimen, las guerras y, sobre todo, los problemas financieros de la Real Hacienda condujeron a la práctica paralización del Arsenal entrando la comarca ferrolana en una fase depresiva hasta la década de los cuarenta del siglo $\mathrm{XIX}^{8}$. Solamente los contratos de construcción con la casa comercial de Manuel Ciarán salvaron de la inacción al establecimiento durante las décadas de los veinte y treinta9

\section{Gráfico 2}

La actividad constructora en el Arsenal de Ferrol, 1860-1914

(tonelaje de construcción en ejecución)

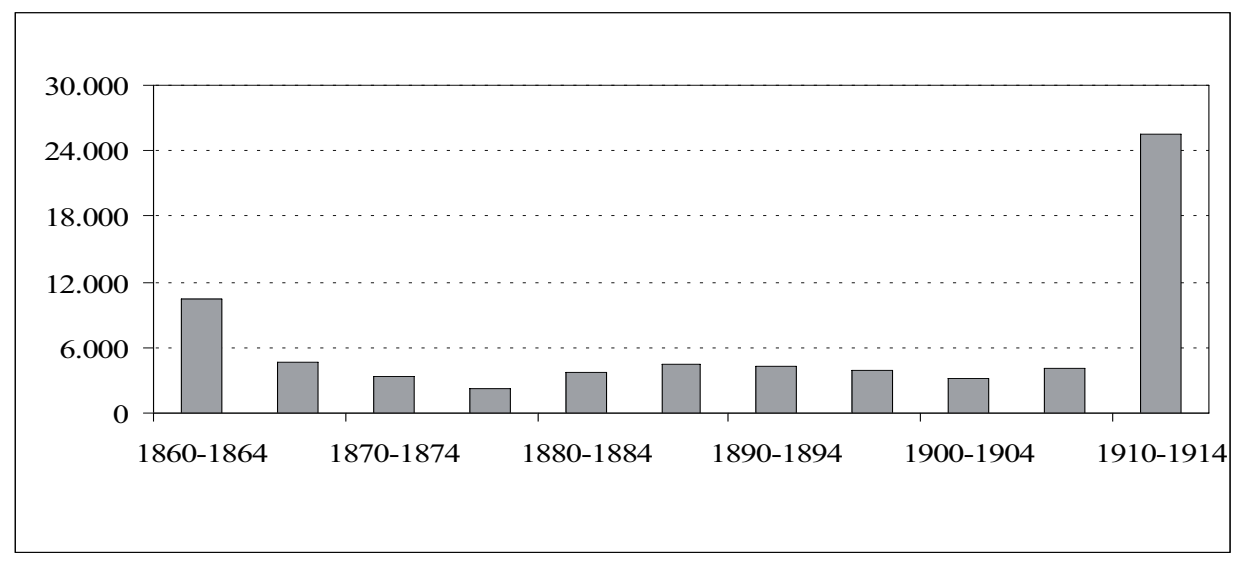

Fuente: Lozano (1997: 117).

\footnotetext{
${ }^{7}$ En ocasiones, el Ayuntamiento y las instituciones religiosas de la región se prestaron a cubrir los salarios de los trabajadores del Arsenal, véase Brey (1984).

${ }^{8}$ Las fábricas de harina de Neda, las de curtidos e incluso la fábrica de cobrería de Xubia se vieron afectadas negativamente por la poca actividad constructora del Arsenal, véase Carmona y Nadal (2005: 107-108). Penedo (1995: 30-35) también establece una relación directamente proporcional entre el desarrollo del Arsenal y otras actividades que se desarrollaron en el entorno ferrolano, tales como la fábrica de tejidos del Roxal.

${ }^{9}$ Esta casa poseía un pequeño astillero privado en la ría de Ferrol, véase Carmona y Nadal (2005: 107-108).
} 
En conjunto, el siglo XIX fue testigo de una actividad menos intensa en el Arsenal estatal, exceptuando los decenios de los cincuenta y sesenta. De hecho, el nivel de actividad alcanzado en 1860 no se repitió hasta la segunda década del siglo XX, cuando la gestión del establecimiento pasó a manos privadas (gráfico 2). La etapa depresiva iniciada casi medio siglo antes empezó a detenerse a partir de 1847, cuando se procedió a realizar importantes obras en las instalaciones del Arsenal ${ }^{10}$. La inauguración del dique de la Campana se enmarca en esta nueva coyuntura ${ }^{11}$. Sin embargo, la segunda mitad del siglo XIX no presentó un comportamiento homogéneo.

Entre 1850 y 1864 el ritmo de construcción manifestó una progresión constante, reflejada en el incremento de la mano de obra en la Maestranza ${ }^{12}$. Ésta ocupaba unos 729 trabajadores en torno a 1846, mientras que hacia 1860 esa cifra había ascendido hasta $3.661^{13}$. Posteriormente, se entró en una etapa de estancamiento que abarcó desde finales del reinado de Isabel II hasta la llegada al poder de Sagasta a comienzos de la década de los ochenta ${ }^{14}$. El Plan de Escuadra de 1887 abrió nuevas expectativas de un futuro más favorable pero pronto se vieron frustradas ${ }^{15}$. El panorama no se aclaró hasta que la Sociedad Española de Construcción Naval (1909) se hizo cargo de la ejecución de las obras previstas en el Programa Naval de 1908 y de gestionar las zonas industriales de los arsenales españoles ${ }^{16}$. El Arsenal ferrolano fue uno de los beneficiados por esa nueva política. Así, la demanda de buques por parte de la Armada volvía a impulsar la moderna construcción naval.

¿Respondía la oferta empresarial de la ciudad de Ferrol a esa evolución? Aunque Lozano (1997) señala que el Arsenal de Ferrol estaba escasamente vinculado a su entorno, en el sentido de generar pocos efectos de arrastre sobre otras industrias de la región, parece claro que sus frecuentes retrocesos durante el XIX tuvieron que plasmarse también en otras empresas que se pudieron haber abordado ${ }^{17}$. La inactividad del Arsenal Ferrolano no animaba la creación de otras iniciativas en la ciudad o en los alrededores, que podían haberse aprovechado de las externalidades positivas que generase la construcción naval militar. Así se deduce del perfil empre-

\footnotetext{
${ }^{10} \mathrm{El}$ nuevo impulso se tradujo en la construcción de varios astilleros particulares en las riberas de la ría ferrolana, donde según Montero (1972: 131-132) se construían buques mercantes de gran porte.

${ }^{11}$ Brey (1984).

${ }^{12}$ Brey (1984).

${ }^{13}$ Montero (1972: 385).

${ }^{14}$ Penedo (1995: 30-35).

${ }^{15}$ Los créditos destinados al funcionamiento del astillero fueron recortados a finales del verano de 1887, véase Brey (1984).

${ }^{16}$ Esta empresa privada, participada en un $40 \%$ por capital británico en el momento de su formación, mejoró la capacidad industrial de los arsenales, véase Lozano (1996: 379) y Lozano (1999: 69-89).
}

${ }^{17}$ Lozano (1997: 487). 
sarial ferrolano durante la primera mitad del Ochocientos (gráfico 3) ${ }^{18}$. Ese perfil, obtenido a partir de la serie temporal de sociedades mercantiles, muestra una tendencia ascendente desde comienzos de la serie, interrumpida durante la década de los treinta, que vio nacer únicamente dos nuevas sociedades, hasta finales de los años ochenta para luego decaer en el período finisecular. Por consiguiente, dos grandes etapas destacan en la evolución económica ferrolana decimonónica desde el punto de vista de la iniciativa privada. Grosso modo, la primera comprende el período 1820-1889, mientras que la última se correspondería con el intervalo 18901914, caracterizado por el empeoramiento de las expectativas empresariales. La respuesta a nuestra pregunta inicial es, por tanto, afirmativa, al manifestarse un paralelismo bastante acusado entre la constitución de sociedades en la ciudad de Ferrol y los progresos de la construcción naval.

\section{Gráfico 3}

Sociedades mercantiles constituidas en Ferrol, 1820-1914

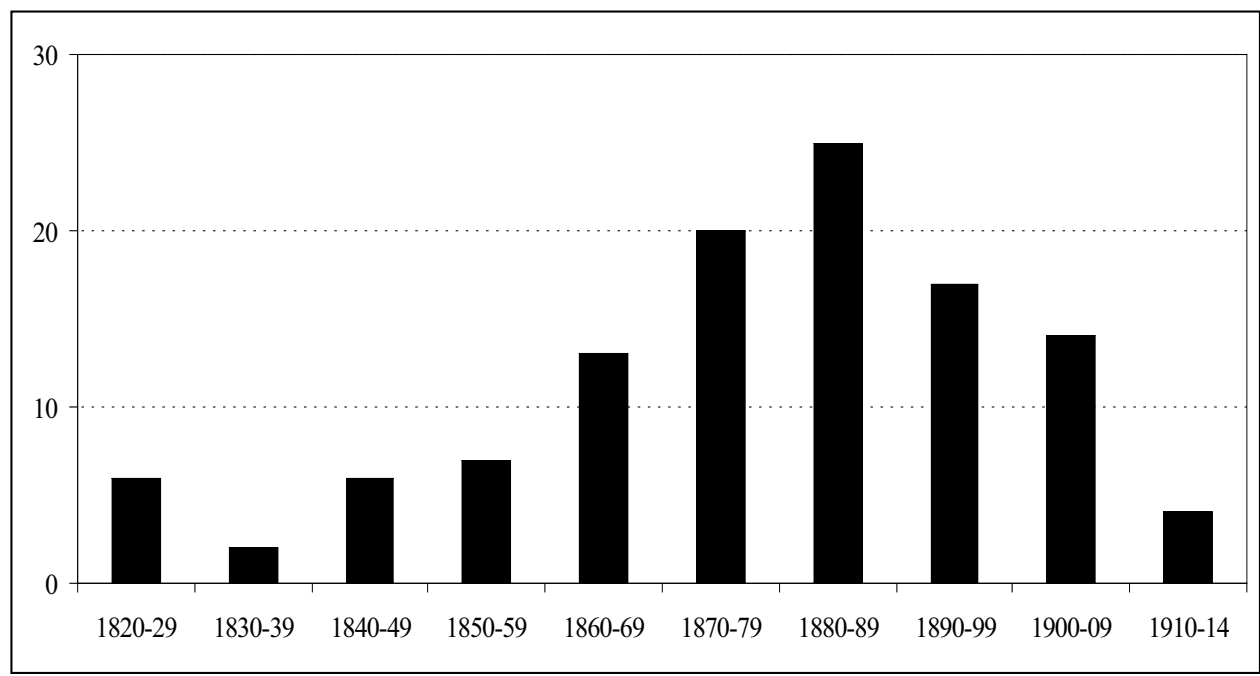

Fuentes: AHPC (Archivo Histórico de Protocolos Notariales de A Coruña) distrito de Ferrol, RMA (Registro Mercantil Antiguo) ${ }^{19}$, RMM (Registro Mercantil Moderno).

${ }^{18}$ La serie recoge las iniciativas privadas que adoptaron la forma de una sociedad colectiva, comanditaria o anónima, entre otros regímenes sociales. Por lo tanto, no incluye lo que había sido el principal factor impulsor del crecimiento ferrolano desde la segunda mitad del Setecientos, el Arsenal.

${ }^{19}$ Archivo del Reino de Galicia, Libro para la toma de razón de los documentos que al efecto presentan los comerciantes con arreglo a la segunda sección del artículo 22 del Código de Comercio, decretado, sancionado y promulgado por S. M. en 30 de mayo de 1829, 2 vols. 
En conjunto, se constituyeron 114 sociedades en Ferrol entre 1820 y 1914, concentradas en el período 1820-1889. El ritmo anual de constitución fue bastante reducido en comparación con las cifras coruñesas, compostelanas y viguesas (gráfico 4). Este distinto ritmo se tradujo en una alteración del atlas empresarial de la fachada atlántica gallega. Éste, a principios del Ochocientos, tenía como capitales económicas a A Coruña, Ferrol y Santiago, pero a finales de la centuria la jerarquía empresarial se había alterado a favor de A Coruña y Vigo que polarizaron el crecimiento, frente a los dos rezagados, Santiago y, especialmente, Ferrol.

Las dos primeras décadas del siglo XIX no mostraron grandes cambios en Ferrol con respecto a otras poblaciones en cuanto a la tendencia de creación de sociedades (gráfico 4). Las diferencias entre las tres principales poblaciones de la provincia coruñesa no eran todavía demasiado evidentes. A Coruña, Santiago y Ferrol se aproximaban bastante en cuanto al número de compañías constituidas, pero la década de los cuarenta implicó el inicio de una fase de crecimiento para la economía herculina, que no se manifestó por igual en los tres grandes núcleos de población provinciales. Sus trayectorias empezaron a divergir a partir de dicho decenio. Una vez finalizada la primera guerra carlista, Ferrol sigue una fase ascendente más suave que la herculina y la compostelana, aunque la renovación del ímpetu empresarial durante el período 1840-1889 fue un rasgo compartido por los tres núcleos coruñeses. Sin embargo, la década de los años ochenta abrió las puertas al período de mayor crecimiento en la historia decimonónica coruñesa con la excepción de la ciudad ferrolana.

A Coruña fue indudablemente el núcleo más activo dado que su progreso fue más rápido y comenzó a distanciarse gradualmente. La ciudad herculina concentró en torno a la mitad del sector industrial provincial. La presencia de diversas industrias de consumo y las rentas de situación que le proporcionaba el puerto la convirtieron en el núcleo urbano más desarrollado en el siglo XIX. Vigo avanzaba gradualmente al ritmo de los cambios que experimentaba el sector industrial de los transformados de la pesca. Sin embargo, estos cambios no le habían permitido todavía rebasar a la principal economía urbana de la región, A Coruña. Mientras tanto, Santiago y Ferrol se quedaron rezagados frente al avance capitalino y tendieron a converger conforme nos acercábamos a la Gran Guerra. 


\section{Gráfico 4}

Sociedades e inversión en las grandes ciudades gallegas, 1820-1914
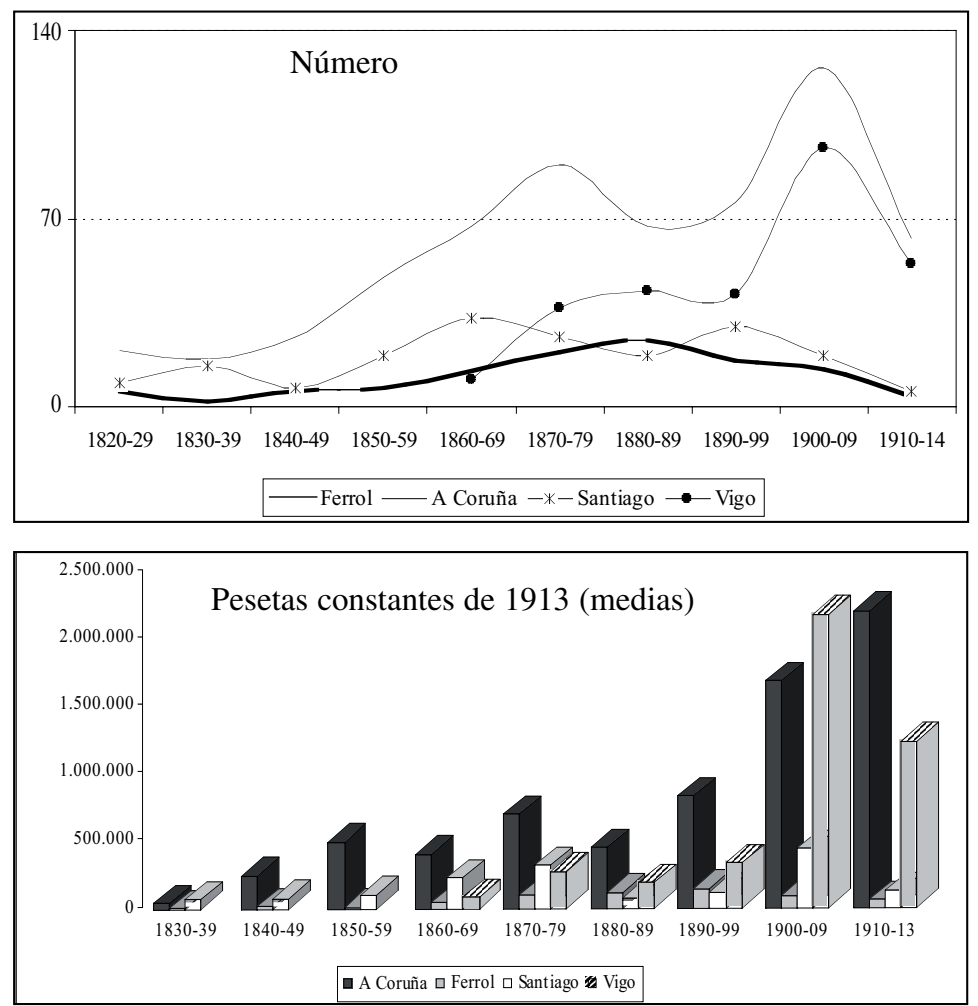

Notas: la serie viguesa se inicia en 1866. El deflactor empleado ha sido Maluquer (2005: 1290-1291). Fuentes: AHPC, distritos de A Coruña y Ferrol, AHUSC (Archivo Histórico Universitario de Santiago de Compostela), RMA, RMM y Abreu (2002: 73-93).

Así, el período finisecular muestra las mayores diferencias en el comportamiento de las cuatro urbes: A Coruña, Vigo y, en menor medida, Santiago siguieron un ritmo dispar frente al ferrolano. Mientras las dos primeras experimentaban un «boom» finisecular, Ferrol entraba en una fase recesiva. Por ejemplo, A Coruña registró cifras medias de constitución de compañías mercantiles que multiplicaban por más de siete las ferrolanas entre 1890 y 1914. De tal forma que el $66 \%$ de las sociedades constituidas en la provincia coruñesa durante el período 1890-1913 radicaron en la capital herculina, mientras que Santiago captó el 14\% y Ferrol un escaso $9 \%$. Compostela presentó una tendencia similar a la ferrolana aunque no tan acusadamente negativa, al menos en el período finisecular. 
Los capitales invertidos reincidían en esta pauta, pero con mayor intensidad. Ferrol y Santiago registraron los menores niveles de inversión en sociedades en la provincia de A Coruña. Por el contrario, los más elevados se alcanzaron en la capital herculina entre 1890 y 1913. A Coruña concentró aproximadamente el $74 \%$ del capital, Santiago alrededor del 13\% y Ferrol en torno al 5\%. Así, Ferrol presentó cifras de inversión muy bajas que sólo experimentaron un pequeño repunte entre la década de los setenta y la de los noventa. En cambio, la capital herculina presentaba una capitalización media superior. Un fenómeno que se repitió también en el caso de Vigo respecto al conjunto de la provincia de Pontevedra durante el mismo período.

En resumen, los caminos de las tres ciudades coruñesas se alejaron en los años finiseculares y la capital coruñesa cobró un protagonismo absoluto en el desarrollo provincial. Ferrol estaba a la cola de la actividad empresarial provincial. Este núcleo alcanzó el máximo en constitución de sociedades a principios de los ochenta, para luego descender y no volver a recuperarse hasta la siguiente centuria. En cambio, A Coruña reanudó el crecimiento abortado por la crisis finisecular, dándole un nuevo y mayor impulso. Santiago, que volvió a alcanzar niveles de constitución de compañías cercanos a los conseguidos a principios de los setenta, no experimentó un crecimiento tan intenso como el coruñés pero fue superior al ferrolano. Todo apunta a que el sector empresarial ferrolano seguía sus propios ritmos, ritmos en sintonía con los que experimentaba la actividad de los astilleros estatales.

\section{RAQUITISMO INDUSTRIAL Y EXPANSIÓN COMERCIAL}

La dependencia del Arsenal fue una constante en la evolución de la economía ferrolana durante el siglo XIX. Sin embargo, Ferrol también poseía un sector privado industrial, aunque el análisis de la estructura empresarial de Ferrol durante el siglo XIX nos revela una ciudad bastante «pobre» en términos industriales, comparada con A Coruña y Vigo. Entre los papeles y oficios del Gobierno Político de la provincia de A Coruña encontramos algunas apreciaciones muy ilustrativas que reflejan el desolador panorama industrial de Ferrol y sus alrededores en 1835:

«[...] que en la villa de Ferrol y la Graña no hay fábricas de curtido, papel, paños ni otras semejantes que merezcan el nombre de tales, y solo en el lugar del Castillo de S. Felipe hay almacenes que se denominan Fábricas de Salazón de sardina en que se elabora abadejo, merluza, congrio... sin haber número fijo de operarios por depender de la temporada y mes del año» ${ }^{20}$.

${ }^{20}$ AMF (Archivo Municipal de Ferrol), Disposiciones superiores sobre industria e comercio, Caja 473-A, Expediente 6, ff. 165-268. 
La situación industrial no mejoró excesivamente durante el resto del siglo. Algunos informes elaborados por el Ayuntamiento de Ferrol dan cuenta de la escasez industrial. Aunque aquéllos adolecen frecuentemente de exhaustividad y coherencia ofrecen una imagen bastante aproximada de esa pobreza manufacturera en fechas tan avanzadas como 1876 y 1901-1902 (cuadro 1).

\section{Cuadro 1}

Relación de fábricas y otros establecimientos en el Ayuntamiento de Ferrol, 1876-1902

\begin{tabular}{|c|c|c|c|c|c|c|}
\hline \multirow{2}{*}{ Fábricas } & \multirow[b]{2}{*}{1876} & \multicolumn{5}{|c|}{ 1901-1902 } \\
\hline & & 1901-1902 & \multicolumn{4}{|c|}{ Talleres y otros establecimientos } \\
\hline Gaseosas & - & 3 & Panadería & 17 & Alfarería & 2 \\
\hline Cerveza & 1 & - & Bollería & 4 & Taller de ataúdes & 3 \\
\hline Molino harinero & 6 & - & Confitería & 3 & Taller de bronces & 4 \\
\hline Pastas & 2 & 1 & Sastrería & 26 & Taller de motonería & 1 \\
\hline Chocolate & 1 & 2 & Sombrerería & 5 & Taller de construcción de carruajes & 2 \\
\hline Almidón & 2 & - & Zapatería & 14 & Taller de herrador & 2 \\
\hline Jabón & 1 & - & Guarnicionería & 4 & Taller de herrería & 5 \\
\hline Velas & 2 & 4 & Botería & 2 & Hojalatería & 11 \\
\hline Calzado & - & 1 & Taller de tapicería & 4 & Taller de platería & 1 \\
\hline Cacharrería & 2 & - & Taller de encuadernación & 2 & Taller de engarzar piedras falsas & 6 \\
\hline Aserradero & 1 & - & Tipografía & 4 & Taller de relojería & 2 \\
\hline Alumbrado eléctrico & - & 1 & Taller de mármoles & 2 & Fotografías & 5 \\
\hline \multirow[t]{3}{*}{ Total } & 18 & 11 & Carpintería & 3 & Tintorería & 5 \\
\hline & & & Ebanistería & 13 & Veterinario & 1 \\
\hline & & & & & Total & 153 \\
\hline
\end{tabular}

Fuente: AMF, Disposiciones superiores sobre industria y comercio, Expedientes: Fábricas instaladas no distrito. Año 1876, Estado del número de fábricas establecidas en este distrito reclamado por Circular del Gobierno de Provincia, Caja 1558, Expte. 6-bis; AMF, Disposiciones superiores sobre industria y comercio, Estadísticas, 1901-1902: Extranxeiros residentes en talleres e fábricas, Caja 271-A.

La industria ocupó un segundo puesto en las preferencias del sector empresarial ferrolano. El sector manufacturero representó la quinta parte aproximadamente de las sociedades constituidas y en torno al 37\% del capital entre 1820 y 1914 (cuadro 2). La industria textil, los curtidos, la construcción naval, los aserraderos y las imprentas así como la industria alimenticia absorbieron el grueso de la exigua industria ferrolana decimonónica. Las sociedades constituidas sobre aserraderos e imprentas no fueron excesivamente numerosas pero se distinguen por la singular atracción que ejercieron sobre algunos inversores a finales del siglo XIX y comienzos del XX (véase apéndice y cuadro 2). 
Además, la participación de la ya reducida industria ferrolana se contrajo en el período finisecular. Esta contracción fue acompañada de una paralela expansión del sector terciario entre 1890 y 1913. El sector industrial, excluyendo la construcción y el energético, pasó de representar el $21 \%$ de las sociedades creadas entre 1820 y 1889, a representar un $14 \%$ de las mismas entre 1890 y 1914. Por el contrario, el sector servicios ascendía del $64 \%$ al $77 \%$. Todo ello apunta a que el sector terciario se estaba convirtiendo en el refugio del empresariado ferrolano ante la decadencia del ritmo de construcciones en los astilleros. Entre 1891 y 1913 únicamente se crearon cinco sociedades fabriles, concentrándose el grueso de la inversión en la construcción naval privada.

\section{Cuadro 2}

Estructura empresarial en Ferrol, 1820-1914

(pesetas corrientes)

\begin{tabular}{|c|c|c|c|c|c|c|c|c|c|c|c|c|}
\hline & \multicolumn{4}{|c|}{$1820-1889$} & \multicolumn{4}{|c|}{$1890-1914$} & \multicolumn{4}{|c|}{$1820-1914$} \\
\hline & n. ${ }^{0}$ & $\%$ & pts & $\%$ & n. ${ }^{0}$ & $\%$ & pts & $\%$ & n. ${ }^{0}$ & $\%$ & pts & $\%$ \\
\hline Pesca & 2 & 2,5 & 22.500 & 0,9 & - & - & - & - & 2 & 1,8 & 22.500 & 0,4 \\
\hline Minería & 3 & 3,8 & 30.000 & 1,2 & 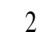 & 5,7 & 6.130 & 0,2 & 5 & 4,4 & 36.130 & 0,7 \\
\hline Industria & 19 & 24,1 & 1.017 .492 & 39,9 & 5 & 14,3 & 854.605 & 33,6 & 24 & 21,1 & 1.872 .097 & 36,7 \\
\hline Salazón & 3 & 3,8 & 37.500 & 1,5 & - & - & - & - & 3 & 2,6 & 37.500 & 0,7 \\
\hline Otra alimenticias & 3 & 3,8 & 53.643 & 2,1 & - & - & - & - & 3 & 2,6 & 53.643 & 1,1 \\
\hline Bebidas & 2 & 2,5 & 8.784 & 0,3 & - & - & - & - & 2 & 1,8 & 8.784 & 0,2 \\
\hline Textil & 6 & 7,6 & 103.330 & 4,0 & - & - & - & - & 6 & 5,3 & 103.330 & 2,0 \\
\hline Curtidos & 3 & 3,8 & 369.237 & 14,5 & - & - & - & - & 3 & 2,6 & 369.237 & 7,2 \\
\hline Madera y corcho & - & - & - & - & 2 & 5,7 & 130.000 & 5,1 & 2 & 1,8 & 130.000 & 2,6 \\
\hline Papel y edición & - & - & - & - & 2 & 5,7 & 321.605 & 12,6 & 2 & 1,8 & 321.605 & 6,3 \\
\hline Química & - & - & 5.000 & 0,2 & - & - & - & - & - & - & 5.000 & 0,1 \\
\hline Construcción naval & 1 & 1,3 & 440.000 & 17,2 & 1 & 2,9 & 403.000 & 15,8 & 2 & 1,8 & 843.000 & 16,5 \\
\hline Otras industrias & 1 & 1,3 & n.d. & n.d. & _- & - & - & - & 1 & 0,9 & - & - \\
\hline Energía & - & - & - & - & 1 & 2,9 & 250.000 & 9,8 & 1 & 0,9 & 250.000 & 4,9 \\
\hline Construcción & 3 & 3,8 & 211.576 & 8,3 & - & & - & & 3 & 2,6 & 211.576 & 4,2 \\
\hline Comercio & 44 & 55,7 & 1.243 .407 & 48,7 & 23 & 65,7 & 1.202 .773 & 47,3 & 67 & 58,8 & 2.446 .180 & 48,0 \\
\hline Hostelería & 1 & 1,3 & 5.000 & 0,2 & - & & - & - & 1 & 0,9 & 5.000 & 0,1 \\
\hline Transporte, almac., comunic. & 2 & 2,5 & 22.871 & 0,9 & 2 & 5,7 & 179.022 & 7,0 & 4 & 3,5 & 201.893 & 4,0 \\
\hline Finanzas y seguros & - & - & - & - & 2 & 5,7 & 50.445 & 2,0 & 2 & 1,8 & 50.445 & 1,0 \\
\hline Inmobiliarias y serv. personal & 1 & 1,3 & n.d. & n.d. & - & - & - & - & 1 & 0,9 & - & - \\
\hline Servicios a la Admon. pública & 2 & 2,5 & n.d. & n.d. & - & - & - & - & 2 & 1,8 & - & - \\
\hline Otros servicios & 2 & 2,5 & n.d. & n.d. & - & - & - & - & 2 & 1,8 & - & - \\
\hline Total & 79 & 100 & 2.552 .847 & 100 & 35 & 100 & 2.542 .976 & 100 & 114 & 100 & 5.095 .822 & 100 \\
\hline
\end{tabular}

Fuentes: AHPC, distrito de Ferrol, RMA, RMM. 
Una de las pocas novedades en la industria finisecular fue la incorporación de Ferrol a la corriente de inversión en energía eléctrica a través de la sociedad anónima Eléctrica Popular Ferrolana (1894). Esta modesta fábrica se dedicó al alumbrado eléctrico público y privado con un capital de 250.000 pesetas $^{21}$. Sus primeros clientes fueron algunos establecimientos de la ciudad, las viviendas de los ciudadanos más notables e incluso alguna dependencia municipal ${ }^{22}$. En 1893, contrató con la corporación municipal el servicio de alumbrado público que hasta entonces había estado en poder de la Sociedad General de Alumbrado de España y Portugal $^{23}$. Sin embargo, la concesión definitiva fue obtenida, tras subasta pública, por la Sociedad General Gallega de Electricidad en $1901^{24}$. La disolución de la compañía eléctrica local tuvo lugar un año después tras su venta a la Sociedad General Gallega de Electricidad ${ }^{25}$.

En realidad, el reducido tejido empresarial ferrolano estuvo dominado por el sector terciario. Casi el $70 \%$ de las sociedades constituidas en Ferrol entre 1820 y 1914, que representaban a su vez el 53\% del capital, se encuadraban en ese sector (cuadro 2). Las empresas comerciales, especialmente las dedicadas a «géneros ultramarinos, del Reino y extranjeros» y a la venta de tejidos, encabezaron el escalafón terciario de Ferrol. Determinadas actividades como las inmobiliarias, los servicios a las empresas y a la Administración pública tuvieron también una participación notable en la economía ferrolana. Estos servicios prestados a la Administración pública hacían referencia a un pequeño conjunto de sociedades constituidas para acudir a las licitaciones de las obras públicas, obtener contratos con el Arsenal ferrolano y, en general, participar en todo tipo de contratos públicos. La obtención de contratas con el Estado y la Marina, entre las que incluimos el suministro de

\footnotetext{
${ }^{21}$ Siete vecinos de Ferrol, Gabriel Antón Castillo, propietario, Antonio Barreiro Sánchez, comerciante-banquero, Diego Castro Fuguera, maquinista de la Armada, Andrés Avelino Comerma Batalla, ingeniero e inspector de la Armada en reserva, Emilio González Buyo, comerciante, Justo González Salorio, maquinista de la Armada y Antonio Togores Corvina, propietario, retirado de la Marina y su presidente, figuraron como socios en la escritura de constitución, RMM (1894) n. ${ }^{\circ}$ 118, libro 7, f. 41.

${ }^{22}$ Sus generadores estaban en una nave construida en el cruce de la calle del Sol con la de la Muralla, la actual Avenida del Rey, véase Valdivieso (2000).

${ }^{23} \mathrm{El}$ contrato con la Sociedad General de Alumbrado de España y Portugal, luego llamada Sociedad Catalana para el Alumbrado por Gas, se produjo en 1882, véase Valdivieso (2000).

${ }^{24}$ RMM (1900) n. ${ }^{\circ} 467$, libro 17, f. 325.

${ }^{25} \mathrm{La}$ venta se efectuó por 430.218 pesetas, de tal forma que a cada una de las 2.500 acciones les correspondió 114 pesetas. Los antiguos accionistas podían tomar acciones de la Sociedad General Gallega de Electricidad en la proporción de 1 a 5 de la antigua compañía, RMM (1894) n. ${ }^{\circ} 118$, libro 7 , ff. 41 y ss.
} 
todo tipo de efectos al Arsenal de Ferrol, estuvo entre los objetivos de varias firmas como Pradenhes, Rodríguez y Stoll (1873), Hijos de Santos Galán (1885) y Leiceaga y Poublan (1892). Muchas de estas empresas combinaban su actividad principal (farmacia, comercio de ultramarinos y de tejidos, entre otros) con la ejecución de dichas contratas. Esto sucedía también con algunas de las más relevantes casas de comercio del casco urbano, tales como Fernández Hnos y Pedro Maristany y Cia. Así, la principal industria ferrolana, el Arsenal, también impulsaba la formación de sociedades destinadas a cubrir sus demandas o, en todo caso, generaba nuevas ramas de negocio para alguna de las empresas ya existentes. Montero (1972: 303-308) afirma incluso que el comercio de Ferrol fue dependiente en gran medida del estado contable de la tesorería de Marina.

El comercio fue el objeto social de la mayor parte de las sociedades constituidas en Ferrol durante el siglo XIX. El ranking de empresas comerciales ferrolanas constituidas durante dicha centuria estuvo encabezado por el comercio de bienes de consumo no alimenticios, los coloniales y los productos alimenticios, las bebidas y el tabaco (cuadro 3). En cambio, respecto a la inversión, las compañías dedicadas al comercio de ultramarinos y artículos extranjeros absorbían mucho más capital que aquellas dedicadas al comercio de bienes de consumo no alimenticios. Compañías como Marcelino Álvarez y Cia, Dopico y Carriles, Francisco Botas y Cia y A. Barreiro y Cia dedicados al comercio de géneros ultramarinos, nacionales y extranjeros se encuentran entre las mayores empresas ferrolanas del siglo (véase apéndice). 


\section{Cuadro 3}

El comercio en Ferrol, 1820-1914

(estructura en porcentajes y capital en pesetas corrientes)

\begin{tabular}{|c|c|c|c|c|}
\hline & \multicolumn{4}{|c|}{$\%$} \\
\hline & n. ${ }^{\mathbf{2}}$ & pts & n. $^{\circ}$ & pts \\
\hline Coloniales & 13 & 732.400 & 19,4 & 29,9 \\
\hline Mayorista & 9 & 642.400 & 13,4 & 26,3 \\
\hline Minorista & 4 & 90.000 & 6,0 & 3,7 \\
\hline Extranjeros & 10 & 596.962 & 14,9 & 24,4 \\
\hline Mayorista & 9 & 546.962 & 13,4 & 22,4 \\
\hline Minorista & 1 & 50.000 & 1,5 & 2,0 \\
\hline Materias primas agrarias y animales vivos & 2 & 15.000 & 3,0 & 0,6 \\
\hline Mayorista & 1 & 15.000 & 1,5 & 0,6 \\
\hline Alimenticios, bebidas y tabaco & 11 & 150.273 & 16,4 & 6,1 \\
\hline Mayorista & 3 & 97.029 & 4,5 & 4,0 \\
\hline Minorista & 1 & n.d. & 1,5 & n.d. \\
\hline Bienes de consumo no alimenticios & 17 & 430.563 & 25,4 & 17,6 \\
\hline Mayorista & 1 & 60.346 & 1,5 & 2,5 \\
\hline Minorista & 3 & 77.250 & 4,5 & 3,2 \\
\hline No agrarios semielaborados & 5 & 300.100 & 7,5 & 12,3 \\
\hline Mayorista & 4 & 200.100 & 6,0 & 8,2 \\
\hline Otros productos & 3 & 100.000 & 4,5 & 4,1 \\
\hline Sin especificar & 6 & 120.882 & 9,0 & 4,9 \\
\hline Mayorista & 1 & 60.000 & 1,5 & 2,5 \\
\hline Total & 67 & 2.446 .180 & 100 & 100 \\
\hline
\end{tabular}

Fuentes: AHPC, distrito de Ferrol, RMA, RMM.

Dentro del comercio de bienes de consumo no alimenticios, la venta de tejidos de todas clases, seguido de los establecimientos dedicados al comercio de quincalla, ferretería y joyería absorbía el mayor número de compañías. Esta estructura comercial fue la dominante y similar a la presentada por el comercio de la provincia durante el Ochocientos ${ }^{26}$. Sin embargo, tras la década de los ochenta tenderá a aumentar la inversión en el comercio de coloniales más que en los bienes de consumo no alimenticios. Las compañías de coloniales llegaron a absorber más de la mitad de la inversión en el comercio entre 1890 y 1913, un 54,2\%. A su vez, estas empresas representaron en torno al $41 \%$ de las constituidas en dicha ciudad durante el mismo período.

\footnotetext{
${ }^{26}$ Lindoso (2005: 265-267).
} 
Pero Ferrol era un puerto de menor categoría ${ }^{27}$. Además, este núcleo permaneció al margen de la red ferroviaria hasta el siglo XX. Su movimiento comercial era una reducida parte del presentado por los puertos de A Coruña y Vigo, los puertos gallegos con mayor movimiento comercial en el siglo XIX. En concreto, en 1855 las importaciones desde el puerto ferrolano eran el $25 \%$ de las realizadas desde el herculino, y respecto a las exportaciones la distancia era abismal, un $0,3 \%$ (cuadro 4). En los años sesenta mejoró algo la posición de Ferrol respecto al primer puerto gallego del siglo XIX, el herculino. Sin embargo, en 1900 las importaciones ferrolanas era el $16 \%$ aproximadamente de las coruñesas y sus exportaciones el 1,4\%. En cuanto a las exportaciones, su posición exterior había mejorado ligeramente aunque era un puerto con saldo deficitario al igual que los más destacados puertos gallegos.

\section{Cuadro 4}

El puerto ferrolano, 1854-1914

(\% sobre valores del puerto de A Coruña)

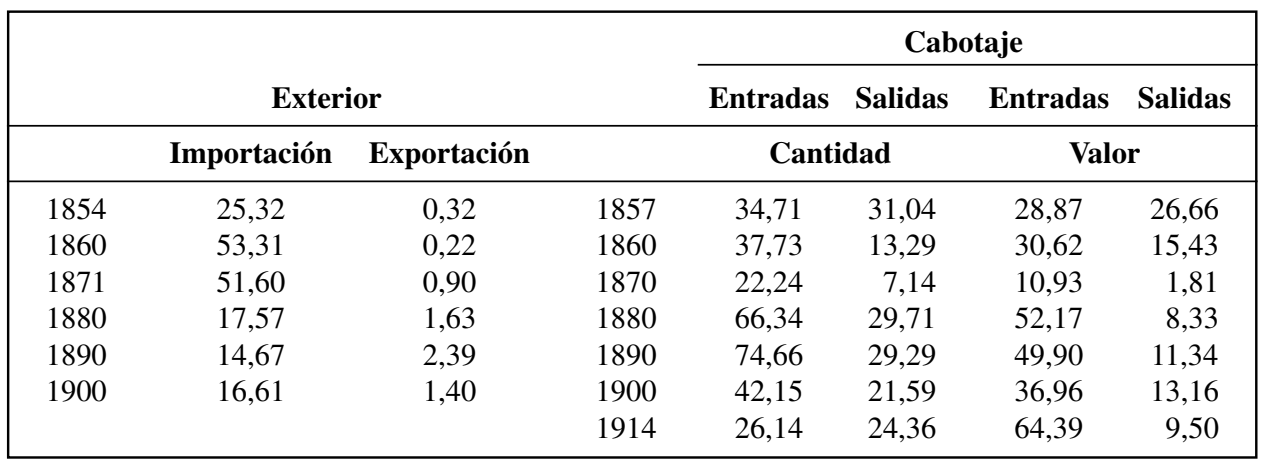

Fuentes: Estadística del comercio de cabotaje de España entre los puertos de la Península e Islas Baleares (18571913). Estadísticas del Comercio Exterior de España (1854-1914).

De hecho, el grueso del comercio marítimo en los puertos del arco atlántico gallego fue básicamente de cabotaje durante la segunda mitad del siglo XIX. Respecto a este tipo de intercambio, los resultados de Ferrol son mejores pero todavía

\footnotetext{
${ }^{27}$ El puerto de Ferrol fue declarado aduana de tercera clase en 1853. Fue habilitado para el comercio general de importación y de exportación, para importar artículos de alquitrán, brea, cáñamo, carbón, cordelería, herrajes, herramientas, jarcias, maderas y tablazón, maquinaria e hilazas con destino a la fábrica del Roxal y comestibles para consumo de la marinería y que no produjese la región, véase Montero (1972: 307).
} 
eran significativamente inferiores a las herculinas. Asimismo, las entradas de mercancías en cabotaje tendieron a superar a las salidas durante la segunda mitad del siglo XIX. Por tanto, Ferrol fue un puerto importador en ambos sentidos.

\section{EL REMANENTE INDUSTRIAL}

Tal y como enunciamos anteriormente la escasa iniciativa privada industrial en la ciudad de Ferrol y su área de influencia estuvo liderada por el sector naval, la elaboración de curtidos y el sector textil. La industria papelera tuvo también bastante relevancia en la comarca. Estos sectores acogieron a las principales firmas industriales del área ferrolana durante el siglo XIX. Sin embargo, hasta la depresión finisecular, el subsector alimenticio, centrado en las tradicionales salazones, la elaboración de bebidas gaseosas y alguna pequeña fábrica de pastas, fue uno de los que aglutinó el mayor número de iniciativas junto al textil. Tras los años ochenta, la industria salazonera perdió claramente terreno en la estructura industrial local, al igual que estaba sucediendo en otros puntos de la región donde esa actividad tradicional estaba siendo suplantada por la moderna industria conservera (cuadro 2). Ferrol, en cambio, no conoció un paralelo desarrollo de la industria conservera que pudiera haber compensado esa decadencia. En consecuencia, en las siguientes páginas nos centraremos en los sectores del cuero, del textil, del papelero y de la construcción naval como principales representantes del acervo industrial ferrolano.

La provincia coruñesa contó con algunos de los principales núcleos de producción del cuero gallego del Ochocientos ${ }^{28}$. En 1804 se contabilizaban 37 fábricas de curtidos en Galicia, de las que diez radicaban en Ferrol, nueve en Santiago, tres en Betanzos y dos en la ría de Noia $^{29}$. La comarca ferrolana fue una de las primeras en acoger la implantación de varias tenerías en la segunda mitad del siglo XVIII ${ }^{30}$. Asimismo, se convirtió en punto de difusión de las operaciones de curtido a otros puntos de la región ${ }^{31}$. Por lo tanto, a comienzos del siglo XIX el área Ferrol-Betan-

\footnotetext{
${ }^{28}$ La localización industrial de esta industria tenía básicamente un carácter rural o extraurbano. Las características intrínsecas al proceso de elaboración del cuero limitaban su situación dentro de las ciudades. Los malos olores y la contaminación medioambiental, así como sus especiales necesidades de inputs, marcaban su emplazamiento extramuros de las ciudades o en distritos rurales.

${ }^{29}$ Fernández Vázquez (2002: 123) citando a Labrada (1809). Véase también la distribución geográfica de las fábricas de curtidos gallegas en 1804 en Nadal (dir.) (2003: 42).

${ }^{30} \mathrm{La}$ declaración de Ferrol como Departamento de Marina fomentó la industria del curtido de pieles, estableciéndose varias fábricas en las riberas del puerto, véase Montero (1972: 406-407). A su vez, la demanda del Arsenal impulsó la creación de la Fábrica de Cobrería de Xubia y de varias fábricas de harinas, véase Carmona y Nadal (2005: 56).

${ }^{31}$ Dos de las primeras fábricas de curtidos coruñesas se establecieron en el arco Betanzos-Pontedeume, una comarca intermedia entre el puerto herculino y el ferrolano, en la década de los setenta del
} 
zos concentraba el mayor número de tenerías. El consumo de artículos de piel se había visto incrementado por el crecimiento demográfico español y, en el caso de Ferrol, sobre todo por la expansión del Arsenal. El sector del cuero gallego continuó creciendo en los años posteriores a la Guerra de la Independencia de forma extensiva. En primer lugar, colonizando nuevos territorios como Vigo, Viveiro y Ponteareas y en segundo lugar, consolidando las tenerías existentes y creando otras nuevas en zonas como Santiago, Noia y Allariz ${ }^{32}$.

\section{Cuadro 5}

Sociedades de curtidos constituidas en la provincia de A Coruña, 1820-1914

(pesetas corrientes)

\begin{tabular}{|c|c|c|c|c|c|}
\hline & Nombre & Capital & & Nombre & Capital \\
\hline \multicolumn{3}{|c|}{ A Coruña } & \multicolumn{3}{|l|}{ Cambre } \\
\hline 1831 & Leoncio de Aspe y Cía & 12.545 & 1842 & Viuda de Lauga e Hijo & 22.750 \\
\hline \multicolumn{3}{|c|}{ Betanzos } & \multicolumn{3}{|c|}{ Santiago } \\
\hline 1821 & Valerio Cadenas y Sobrino y Cía & 54.000 & 1823 & Ituarte e hijo político & 396.276 \\
\hline 1833 & Arias y Lago & 132.500 & 1824 & Francisco Antonio Vilomara y Cía & 13.500 \\
\hline 1840 & Ramón María Rodríguez y Cía & 22.500 & 1824 & Manuel de la Riva e Hijo & n.d. \\
\hline 1862 & Luis María de Bolívar y Cía & 50.000 & 1825 & Domingo Antonio Rosende y Cía & 2.750 \\
\hline 1875 & Lissarrague y Cía & 200.000 & 1829 & Juan Harguindey y Cía & 17.000 \\
\hline 1878 & Hijos de Domingo Etcheverría & 426.250 & 1833 & Viuda de Garra e Hijo & 27.023 \\
\hline \multicolumn{3}{|l|}{ Ferrol } & 1835 & Ramón Patiño y Cía & 5.000 \\
\hline 1827 & Martín Gastesi y Cía & 5.000 & 1837 & Bernardo Aguerre Pesamburo y Cía & n.d. \\
\hline 1830 & Juan Antonio Cristoalena y Cía & 7.500 & 1838 & José Santiago Eleicegui y Cía & 150.467 \\
\hline 1831 & Francisco Rodríguez y Cía & 45.000 & 1849 & Francisco Artime y Sobrino & 80.000 \\
\hline 1832 & Manuel Fernández y Cía & 4.000 & 1854 & De Andrés Rodríguez Hermanos & n.d. \\
\hline 1835 & Magdalena Fabre y Cía & n.d. & 1854 & Riva Hnos. & 485.000 \\
\hline 1835 & Andrés Urgorri y Cía & 16.000 & 1864 & Manuel Pío Moreno y Sobrino & 100.000 \\
\hline 1837 & Francisco Ortega y Cía & 30.000 & 1871 & Harguindey Hnos. & 454.829 \\
\hline 1853 & Joaquina Acuña y Cía & n.d. & 1876 & José de Andrés Rodríguez y Hna. & 125.000 \\
\hline 1862 & Donapetry y Carro & n.d. & 1878 & Viuda de José Santiago Eleizegui y Cía & 160.977 \\
\hline 1863 & Jofre y Linos & 90.000 & 1882 & Antonio Ituarte de La Riva y Cía & 15.000 \\
\hline 1868 & La América* & n.d. & 1892 & Domingo Eleicegui, Dainciart y Cía & 56.500 \\
\hline \multirow[t]{2}{*}{1874} & Carro e Hijos/Carro y Cía & 279.237 & 1894 & Bernardo Maíz & 30.000 \\
\hline & & & 1901 & Santiago Aguerre e Hijo & 70.000 \\
\hline
\end{tabular}

Notas: el año consignado hace referencia al año de constitución de la sociedad. La sociedad Valerio Cadenas y Sobrino y Cia tuvo A Coruña como domicilio social, sin embargo, la explotación se llevaba a cabo en Betanzos. (*) la fecha de formación de la sociedad La América data de 1868, sin embargo otras referencias como la indicada por Carmona y Fernández (2003: 45) apuntan a 1864 como el año de fundación de esta empresa.

Fuentes: RMA, RMM, AHUSC y AHPC, distrito de Ferrol.

siglo XVIII. Ambas fueron construidas por dos empresarios foráneos, el comerciante de curtidos catalán Thadeo Roberes en Pontedeume y el riojano Juan de Muro Pastor en Montellos cerca de Betanzos, véase Meijide (1986: 27-43) y Carmona y Fernández (2003: 26-30).

${ }^{32}$ Carmona y Fernández (2003: 31-34). 
Sin embargo, durante el Ochocientos se produjeron cambios importantes en la distribución espacial del cuero gallego (cuadro 5). Ferrol fue, precisamente, una de las áreas más perjudicadas. La decadencia del Arsenal de Ferrol en los primeros años del XIX arrastró también a la fabricación de curtidos en la comarca ${ }^{33}$. Las guerras con Inglaterra, la guerra de la Independencia (1808-1814) y la emancipación de las colonias americanas (1812-1825) empeoraron la situación en el primer cuarto del siglo XIX ${ }^{34}$. Estos fenómenos supusieron un incremento de los costes productivos y de transacción para el área Ferrol-Betanzos. Las fábricas tendieron a instalarse en los lugares donde existían otras alternativas para aliviar la escasez de cueros en caso de que se redujesen las entradas coloniales. Por ejemplo, el acceso a las pieles brasileñas a través de Portugal facilitó el desarrollo de las tenerías compostelanas ${ }^{35}$. Así, la crisis que en las primeras décadas del Ochocientos registró la antaño principal productora de cueros, la comarca ferrolana, favoreció al área compostelana. Desde el punto de vista de las sociedades mercantiles, la hegemonía de Compostela fue clara: veinte sociedades de curtidos constituidas durante el siglo XIX, una cifra no superada ni por Ferrol ni por Betanzos en el mismo período.

En estas últimas poblaciones, sólo se fundaron tres nuevas sociedades dedicadas al curtido de pieles entre 1820 y 1914. Sin embargo, esta cifra es superior si incluimos aquellas sociedades con domicilio social en parroquias cercanas a esos núcleos urbanos y que formaban parte de sus respectivas áreas de influencia. Entonces, en el caso de Betanzos la cifras se doblarían, mientras que para Ferrol se cuadriplicarían si incluimos las de las parroquias de Barallobre, Serantes y Maniños (cuadro 5). En consecuencia, el peso de las comarcas de Ferrol y Betanzos todavía era significativo en el siglo XIX, pero el proceso de creación de nuevas sociedades se detuvo en los años setenta.

En concreto, fruto del estancamiento que vivía el área ferrolana se produjo un fenómeno de adquisiciones y arriendos de las antiguas tenerías a lo largo del siglo. La decadencia de dichas instalaciones se reflejaba, entre otras cosas, en el bajo precio que alcanzaban en el mercado inmobiliario. Así, en 1878 los herederos de Carlos Mouriz vendieron su participación en una fábrica de curtidos deteriorada, de dimensión media, situada en el Monte (Neda) por 300 pesetas. La tenería del Pun-

\footnotetext{
${ }^{33}$ Carmona y Fernández (2003: 34-36).

${ }^{34}$ Un posible elemento relacionado con la decadencia del sector en la zona ferrolana pudo ser la entrada en vigor de la Real Cédula de 25 de septiembre de 1794, también denominada Decreto de Internación. Éste obligaba a los franceses a establecerse a una determinada distancia de los puertos y fronteras, lo que posiblemente perjudicó a los propietarios y maestros extranjeros del cuero ferrolano, véase Fernández Vázquez (2002: 151-157).

${ }^{35}$ Fernández Vázquez (2002: 67-69).
} 
tal, en desuso y bastante ajada, se arrendó por ochenta pesetas anuales en la década de los setenta ${ }^{36}$. Asimismo, Bernardo Donapetri alquiló a los hermanos Marset una tenería en el lugar de la Ribera en la parroquia de Maniños por 160 pesetas anuales durante seis años ${ }^{37}$. A pesar de que ningun área coruñesa especializada en la producción de pieles y cueros quedó al margen de este proceso de adquisiciones y arriendos, la industria del cuero en Ferrol parecía desintegrarse más rápidamente y sin remedio, a pesar de la existencia de algunas fábricas de considerable entidad tales como La América en Pontedeume.

El proceso fue irreversible. A finales del siglo XIX Fernández Negral (2002: 39) citaba sólo cinco tenerías en la ría de Ferrol. En vísperas de la Guerra Civil quedaban en pie únicamente tres tenerías. La segunda mitad del XIX supuso la liquidación o el declive para la mayor parte de las tenerías ferrolanas que fueron cerrando hacia los años sesenta. Por el contrario, Santiago continuó avanzando a trompicones hasta comienzos del siglo XX. En consecuencia, Santiago se erigió en capital del curtido gallego a lo largo del siglo XIX. Casi el 49\% de las nuevas sociedades de curtidos fueron compostelanas y este porcentaje se elevó hasta el $60 \%$ en términos de capital entre 1820 y $1909^{38}$. La inversión media compostelana era superior, lo cual ponía de relieve el mayor tamaño de las mismas. Su evolución no fue homogénea. En concreto, los decenios de 1820 y 1830 fueron los más fructíferos en cuanto a la constitución de sociedades fabriles de curtidos en Santiago de Compostela ${ }^{39}$. A continuación, el ritmo de fundación tendió a decrecer y atravesó una serie de altibajos hasta 1879. Sin embargo, el dominio del cuero compostelano seguía siendo evidente a finales de la centuria. Las sociedades constituidas durante el intervalo 1880-1909 fueron exclusivamente compostelanas ${ }^{40}$.

La industria textil fue otra de las ramas industriales que sobresalió en el sector secundario del área ferrolana. Las sociedades constituidas en este sector representaron en torno al 5\% de las fundadas entre 1820 y 1914 y apenas el $2 \%$ del capital. En cualquier caso, la importancia del sector fue mucho mayor hasta los años ochen-

\footnotetext{
${ }^{36}$ Francisco Riobó Díaz y Cayetano Rodríguez habían comprado anteriormente las existencias de la fábrica, AHPC, Anselmo Varela, leg.2679 (1870), distrito de Ferrol, ff. 69-72.

${ }^{37} \mathrm{El}$ estado de la fábrica no aconsejaba una mayor renta, teniendo en cuenta que Donapetri había adelantado a cuenta de la renta los fondos necesarios para reparar la fábrica y sus almacenes, con el fin de reiniciar las operaciones de la fábrica, AHPC, Anselmo Varela, leg.2664 (1861), distrito de Ferrol, ff. 317-318.

${ }^{38}$ A partir de 1909 no tenemos constancia de la constitución de ninguna sociedad de curtidos en los distritos analizados, véase Lindoso (2005: 140).

${ }^{39}$ Carmona y Fernández (2003: 66) sitúan la edad de oro del curtido compostelano entre 1790 y 1830.

${ }^{40}$ Lindoso (2005: 140).
} 
ta que durante el período finisecular (cuadro 2). Dos grandes iniciativas fabriles textiles destacaban antes de la crisis agraria finisecular: la fábrica de tejidos del Roxal y La Galicia Industrial. Su éxito fue desigual. La iniciativa más temprana fracasó mientras que la segunda empresa ha prolongado su vida hasta la actualidad.

La fábrica de tejidos de Isabel II del Roxal (Neda) fue objeto de explotación por parte de varias sociedades sin que ninguna lograse llevarla a buen término. La Iniciativa Fabril, Garrido Veiga y Cia, Pablo Collado y Cia y José María Arcelús se fundaron sobre dicho establecimiento. Éste fue erigido por el comerciante coruñés Juan de Veiga, que poseía otra fábrica en A Coruña ${ }^{41}$. Las distintas compañías fueron el resultado de la incesante búsqueda de capital para sacar adelante la producción. Veiga se asoció primero con su hermano Tomás y luego con varios capitalistas coruñeses y madrileños ${ }^{42}$. La fábrica fue adquirida a comienzos de la década de 1850 por Victoriano Braña, gerente de la casa de banca Braña, Abella y Cia. La quiebra de esta compañía puso de nuevo en el mercado a la instalación fabril. Los compradores fueron la ya citada casa de comercio ferrolana Fernández Hnos. Pero el establecimiento fue hipotecado varias veces hasta que finalmente acabó en manos de uno de los acreedores de la compañía, José María Arcelús. Este comerciante guipuzcoano llevó a cabo el último intento de levantar la fábrica, formando una nueva sociedad en 1874. Sin embargo, la ausencia de referencias posteriores nos indica que el fracaso persiguió a esta empresa.

Por el contrario, La Galicia Industrial, junto con las firmas textiles La Primera Coruñesa e Hilados y Tejidos de Vilasantar, concentró el grueso de la inversión textil en la Galicia del Ochocientos. La Galicia Industrial tuvo unos capitales bastante significativos para la media regional: comenzó con un capital de 400.000 pesetas que se incrementó hasta casi un millón de pesetas a finales del siglo XIX. Se estableció en la antigua Fábrica Nacional de Moneda y Cobrería de Xubia en las cercanías de Ferrol ${ }^{43}$. El germen de la instalación fabril arranca de 1876, cuan-

${ }^{41}$ La fábrica del Roxal comenzó a funcionar hacia 1843 con maquinaria importada, véase Montero (1972: 408-409).

${ }^{42}$ La falta de capital acosó frecuentemente a Veiga, dado que éste se asoció con dos comerciantes-banqueros coruñeses, Eduardo Santos y Bruno Herce, en la compañía textil coruñesa Herculina. Estos banqueros obtuvieron también una participación en la fábrica del Roxal, AHPC, Francisco Chaves y Alcalde, leg. 8795 (1854), f. 457.

${ }^{43}$ La Real Fábrica de Xubia se puso en marcha en 1803 dedicada a la fabricación de planchas de cobre para la Marina, de fusiles y de monedas de cobre. Las aguas del río Xubia eran la fuerza motriz de la maquinaria de la fábrica así como de varias aceñas, véase Montero (1972: 402-403). Según Carmona (2005: 110) cerró a finales de los sesenta y en sus últimos años se dedicó a la producción de planchas, pernos y clavos de cobre. En 1873, tras una subasta, pasó a manos privadas, primero a las del marqués de San Eduardo y luego a las de Francisco Barcón que la reconvirtió a la producción tex- 
do el comerciante ferrolano Francisco Barcón y Quevedo y el francés Eugenio Foch Abadie fundaron la compañía Barcón y Foch. Su finalidad fue la fabricación de hilados y tejidos de algodón. Dos años después ampliaron el capital mediante la inclusión de un nuevo socio, el comerciante coruñés Angel Paredes Castro. Más tarde, se produjo una nueva ampliación al separarse Foch e integrarse Tomás Cobos y la sociedad Pérez López y Cia. Estos dos últimos entraron en la compañía con el carácter de comanditarios y disfrutando de un sustancioso porcentaje de los beneficios. Pérez López y Cia, dedicados entre otras cosas al comercio de tejidos, se encargaban de distribuir una parte de la producción de la fábrica a través de un depósito establecido en A Coruña percibiendo una comisión del 3\%.

En 1881 se incorporó al objeto social la fabricación de harinas, de cobrería y latón. Sin embargo, esta iniciativa parece no haber fructificado, pues en las renovaciones sucesivas la fabricación de tejidos volvió a ser el objeto principal de la firma. La sociedad se disolvió en 1894, pero esto no significó el fin de la empresa. El fundador de la firma, Francisco Barcón Quevedo, y su hijo, Ubaldo Barcón Sandino formaron una nueva sociedad en 1912, cuyos capitales procedían en gran medida de la antigua fábrica de Barcón y Cia. Finalmente, la fábrica cambió de propietarios en 1928. El nuevo dueño fue el banquero coruñés Dionisio Tejero Pérez, que continuó con la fabricación y prorrogó de esta forma la inversión realizada en su día por la sociedad Pérez López y Cia sobre la misma industria en el último cuarto del Ochocientos ${ }^{44}$.

La influencia de la fábrica fue reducida, pese a la importancia individualizada de la firma, debido a su especialización en tejidos de baja calidad. La producción textil coruñesa se dirigía básicamente a cubrir aquella parte de la demanda regional que quedaba fuera de la competencia del textil catalán ${ }^{45}$. Por consiguiente, su capacidad de expansión era limitada, de la misma manera que su mercado también lo era. En 1930, esa empresa industrial alcanzó un capital desembolsado de tres millones de pesetas y unos activos netos de poco más de 4 millones de pesetas ${ }^{46}$. La factoría continuó con la fabricación de hilados y tejidos y llegó a ocupar más de 400 trabajadores ${ }^{47}$, siendo conocida popularmente como «la fábrica de las sábanas».

til, véase Fernández Negral (1991: 53-55). La reproducción del texto de la subasta de la Fabrica Nacional de Moneda y Cobrería de Xubia, así como la descripción de la finca puede encontrarse en Escrigas (2001).

${ }^{44}$ Los primeros pasos empresariales del empresario herculino Dionisio Tejero Pérez estuvieron ligados a esta compañía y, en concreto, a José López Trigo, uno de los socios de la misma, y para el que comenzó a trabajar en la década de 1870, véase Lindoso (2006).

${ }^{45}$ Carmona (1990: 222).

${ }^{46}$ Carmona y Nadal (2005: 221).

${ }^{47}$ Fernández (1987: 16) y Fernández Negral (1991: 57). 
Otra iniciativa textil de menor entidad fue la que abordaron los hermanos Pedro e Isidro Maristany junto a Nicolás Fernández Díaz y López bajo la razón de Maristany Fernández y Cia (1865). Construyeron un edificio destinado a fábrica de tejidos de lienzo fino y ordinario en Ponte de Xubia (Narón) ${ }^{48}$. Pero esta asociación no produjo los beneficios esperados. Apenas cuatro años después de su formación fue disuelta ${ }^{49}$.

La industria papelera también tuvo cierta significación en la comarca ferrolana. Las riberas del río Belelle acogieron tradicionalmente el establecimiento de varias fábricas de pape ${ }^{50}$. Sin embargo, el siglo XIX fue testigo únicamente del establecimiento de dos nuevas sociedades en este sector. Éstas fueron Juan Rosell y Cia (1848) y Francisco López y Cia (1862) fundadas en Santa María de Sillobre (Fene) y Santa Maria de Neda respectivamente y que explotaban antiguas instalaciones papeleras.

La primera compañía fue creada entre Juan Rosell, residente en Santa María de Sillobre, y Nicasio Tajonera, impresor ferrolano, en $1848^{51}$. La fábrica sobre la que se asentaba estaba situada en el lugar del Carballal en el municipio de Fene, limitando con la fábrica de tejidos del Roxal, y elaboraba fundamentalmente papel de estraza $^{52}$. Pero el mal estado de la misma, aconsejaba su remodelación. Eran necesarias nuevas oficinas y maquinaria para elaborar otro tipo de papel. Además, existían una serie de cargas sobre el edificio, las tierras y las aguas que comprendía. Todo ello exigía capital. Ante la falta de numerario, el dueño de la fábrica, Rosell, resolvió admitir como socio a Tajonera ${ }^{53}$. Éste, en contrapartida a su capital, reci-

\footnotetext{
${ }^{48} \mathrm{El}$ establecimiento lindaba con la fábrica de harinas y los molinos de Lestache pertenecientes a Nicolás Fernández, RMA (1865), f. 125.

${ }^{49}$ RMA (1869), f. 148.

${ }^{50}$ Después del Xubia, el Belelle era el río más notable del partido judicial ferrolano y desembocaba, al igual que el Xubia, en la ría de Ferrol. Según Montero (1972: 402-403) daba impulso a varias fábricas de papel, servía de fuerza motriz a la maquinaria de la fábrica de tejidos del Roxal y de varios molinos maquileros, y a las aceñas sitas en la feligresía de Santa María de Neda. A comienzos del siglo XX, el salto de la Fervenza del Belelle fue aprovechado para producir energía eléctrica. Las primeras sugerencias para aprovechar el potencial de dicho salto partieron primero, del teniente de navío de la Armada, Augusto Miranda Godoy, y luego del fabricante de tejidos Francisco Barcón, véase Valdivieso (2000). Pero, finalmente, fue la Sociedad General Gallega de Electricidad (1900) la que terminó explotándolo.

${ }^{51}$ Seijoso y Malvar (1996) consideran que la imprenta de este conocido hombre de negocios ferrolano fue una de las notables de Ferrol. Sus hijos, Nicasio y Luciano, prorrogaron el negocio paterno. Valdivieso (2003) apunta a que probablemente el papel elaborado era consumido en el taller de impresión del socio capitalista.

${ }^{52}$ AHPC, Anselmo Varela, leg.2678 (1869), distrito de Ferrol, ff. 1431-1435.

53 Juan Rosell era dueño también de unos treinta ferrados de tierra anexos a la fábrica y se servía del agua del río de la Fervenza para los trabajos de la misma. Asimismo, poseía el molino de la Bar-
} 
bió la mitad de los beneficios y se transformó en copropietario. Gracias a la inyección de capital, se pudieron introducir mejoras en el edificio y adquirir la maquinaria necesaria para proceder a elaborar papel blanco ${ }^{54}$. El capital empleado en las reparaciones, la construcción de las nuevas oficinas, la compra de maquinaria y la redención de las pensiones que pesaban sobre el establecimiento fue de 10.714 pesetas, revalorizando así la fábrica. Tajonera continuó con su papel de proveedor de capital en los años siguientes, mientras el maestro Rosell dirigía los trabajos en la fábrica. Dos años después de la formación de la sociedad, Nicasio financió nuevas obras en la fábrica y la adquisición de nueva maquinaria por 5.540,5 pesetas. De esta manera incrementó también su participación en la compañía ${ }^{55}$.

Ésta se disolvió el 15 de septiembre de 1852 cuando Tajonera le compró su parte a Rosell en la fábrica por 6.375 pesetas. Al fallecer Nicasio en 1854, la fábrica pasó a manos de su viuda, Valentina Cabo, y sus dos hijos, Nicasio y Luciano. La viuda acometió una serie de mejoras en la finca construyendo nuevos edificios y mejorando la maquinaria, de tal forma que su valor se estimó en 50.000 pesetas en 1869 . Finalmente, Luciano vendió su parte de la fábrica a su hermano Nicasio ${ }^{56}$. De nuevo, fue enajenada en 1911 a Manuel Nieto Prieto, Pedro Pascual Busquets y Pascual Barragán Jiménez. Terminó sus días reconvertida en molino tras sucesivas enajenaciones durante el siglo $\mathrm{XX}^{57}$.

Éste fue también el destino final de la segunda fábrica sobre la que se constituyó Francisco López y Cia. Francisco López fue el arrendatario de la fábrica sita en el lugar de Fojo, cercano a la fábrica del Roxal, desde $1854^{58}$. En este caso, otra vez las necesidades de capital fueron determinantes para explicar la formación de la

cia situado en la orilla opuesta de la presa de la citada fábrica, en términos de la parroquia limítrofe de Viladonelle. Todos estos bienes estaban valorados en 6.750 pesetas, AHPC, José de la Torre, leg. 2362 (1848), ff. 28-29, distrito de Ferrol.

54 Tajonera tuvo que solicitar un préstamo para realizar esta operación. El Hospital de Caridad le facilitó 7.500 pesetas al interés anual del $6 \%$ durante cuatro años, véase Valdivieso (2003). Según este autor el Cabildo del Hospital reclamó en varias ocasiones el importe del préstamo y los intereses, hasta que finalmente parte de la fábrica acabó en manos de la casa de banca herculina Hijos de Marchesi Dalmau.

55 AHPC, José de la Torre, distrito de Ferrol, leg. 2362 y 2364 (1848, 1850), ff. 28-29 y f. 8.

${ }^{56}$ AHPC, Anselmo Varela, leg.2714 (1881), distrito de Ferrol, ff. 2125-2128. La fábrica fue también hipotecada en varias ocasiones como garantía de algunos créditos, AHPC, Anselmo Varela, leg. 2664 y 2686 (1861, 1872), distrito de Ferrol, ff. 380-381 y 2333-2336.

57 Valdivieso (2003) señala que en sus últimos años producía pasta de madera para la fábrica de La Gandarela (Neda) situada en la orilla derecha del río Belelle.

${ }^{58}$ La fábrica había sido comprada por el comerciante coruñés Francisco Ortega a los herederos de Angel García Fernández por 62.500 pesetas en 1850, AHPC, Ramón Fernández, leg. 9385 (1850), ff. 91 y ss. Cuatro años después Ortega se la arrendó a Francisco López por 1.500 pesetas anuales durante treinta años, AHPC, Ruperto Suárez, leg.9709 (1864), ff. 413 y ss. 
compañía. El arrendatario no podía proseguir el curso normal de los trabajos de elaboración de papel y de molturación de granos por lo que busca socios en las personas de José Quintía, un propietario de Narón y Vicente Gombán, un fabricante de naipes de Narón, a cambio del $85 \%$ de los beneficios ${ }^{59}$. El arriendo a favor de López se rescindió en 1864 debido al incumplimiento por parte del arrendatario de algunas de las condiciones del contrato referentes al cuidado y reparación de los edificios, máquinas y útiles ${ }^{60}$. Pero, poco después, el socio Quintía aforó la fábrica a los herederos de Francisco Ortega por 1.385 pesetas anuales ${ }^{61}$.

El establecimiento presentó una intensa rotación dado que Quintía la alquiló por 2.500 pesetas anuales durante veinte años a Vicente Tellado Vázquez, primer maquinista de segunda clase de la Armada y vecino de La Coruña, y Benito Cortiñas Vázquez, tercer maestro de maquinaria en el Departamento de Ferrol y avecindado en Neda, en 1867. Simultáneamente, Quintía renunciaba a cualquier derecho sobre los productos de la planta ${ }^{62}$. La explotación no permaneció mucho tiempo en esas manos. Tras la muerte de Quintía, su viuda volvió a arrendarla a un fabricante de papel, Ramón Millarengo Manso, vecino de la parroquia de Santa María de Doroña (Vilarmaior), por 4 años y una renta anual en efectivo de 1.385 pesetas $^{63}$. Al final, la fábrica terminó sus días metamorfoseada en molino ${ }^{64}$.

El sector naval privado absorbió también importantes capitales en el Ferrol del siglo XIX. La creación de algunos astilleros privados en la comarca fue un efecto derivado del desarrollo del Arsenal. En concreto, se fundaron dos compañías en Ferrol dedicadas a la construcción y reparación de buques durante dicha centuria, que representaron en conjunto el 16,5\% de la inversión local. Estas sociedades fueron La Industria Española (1885) y Vila y Cia (1890). Ambas poseían un capital superior a la media y explotaban astilleros en la cercana villa de La Graña (véase apéndice).

${ }^{59}$ AHPC, Fermín Formoso, leg. 2542 (1862), ff. 336-340, distrito de Ferrol.

${ }^{60}$ AHPC, Ruperto Suárez, leg.9709 (1864), ff. 413 y ss.

61 Quintía hipotecó como aval de la operación la fábrica de curtidos situada en Ponte de Xubia (Narón) que había adquirido de Manuela Lestache, viuda de Ignacio Acha, AHPC, Ruperto Suárez, leg.9709 (1864), ff. 610 y ss.

${ }^{62}$ AHPC, Manuel Barbeito y Cedrón, leg.2637 (1867), distrito de Ferrol., ff. 1039-1046.

${ }^{63} \mathrm{El}$ arrendatario hipotecó, en garantía del pago de la renta, una fábrica de papel de estraza que comprendía una casa de nueva planta y cuatro molinos harineros situada en la misma parroquia, AHPC, Ramón María Dávila Salgado, leg.2724 (1873), distrito de Ferrol., ff. 97-102. Finalmente, la fábrica se puso a la venta. Valdivieso (2003) indica que la viuda de Quintía vendió la instalación a Antonio Gabriel Emilio Calín Agar por 4.500 pesetas.

${ }^{64}$ Se denominó molino de Alejandro o do Carrizo, en función del nombre de su último propietario, Alejandro Castro Mera, véase Valdivieso (2003). 
El más antiguo era el Astillero y Carenero del Reverbero, perteneciente a Vila y Cia. Inicialmente, había sido construido por la sociedad Abella, Braña y Cia con el fin de acceder a las contratas públicas navales ${ }^{65}$. La quiebra de esta casa de comercio en los años cincuenta significó la desaparición de la sociedad y la puesta a la venta de sus bienes. El comerciante-banquero coruñés Augusto José de Vila y León, uno de sus principales acreedores, adquirió el astillero por 50.000 pesetas ${ }^{66}$. El astillero sirvió en gran medida de catapulta para su negocio naviero ${ }^{67}$. Asimismo, el sector naviero herculino se encontraba entre sus principales clientes ${ }^{68}$.

${ }^{65}$ La construcción comenzó en 1846 en terrenos situados en la ribera de la Graña, junto al enclave del primitivo astillero del Departamento y contiguo a los almacenes de víveres de la Marina, véase Montero (1972: 390-391). Esta importante sociedad se formó en A Coruña en 1847 bajo el nombre de Braña, Abella y Cia, con un capital de 300.000 pesetas aportadas por tres comerciantes: José Víctor Méndez, de Madrid, que aportaba la mitad del mismo, Eugenio Abella, de Ferrol y Victoriano Braña de A Coruña. Méndez se separó un año después de constituirse la sociedad. Ésta fue concebida como una casa de comercio decimonónica en toda la amplitud del término. Su objeto social (todo tipo de negocios tanto con el gobierno como con particulares) se tradujo en su implicación en diversas actividades: el comercio, la banca, el transporte marítimo, la construcción, las contratas públicas, la industria textil y por supuesto la naval. La sociedad estableció a su vez una casa en Ferrol bajo el nombre de Abella, Braña y Cia, RMA (1847-1848, 1855), ff. $42-46$ y 77 y ss. En 1853, se declaró en quiebra técnica dado que el pasivo de ambas casas ascendía a 5.650 .400 pesetas aproximadamente y el activo a 5.069.636 pesetas. Fruto de ello, aprobaron un convenio con sus acreedores, hipotecando varios bienes entre los que estaban el citado astillero y la fábrica de tejidos de Isabel II en el Roxal. Finalmente, se disolvió en 1855, AHPC, Ruperto Suárez, leg. 9698 (1854), ff. 103 y ss.

${ }^{66}$ En realidad, la adquisición del astillero se produjo también a nombre de otros acreedores de la sociedad. Sin embargo, Vila se convirtió en dueño del mismo, AHPC, Ruperto Suárez, leg.9705 (1861), ff. 151-158. Este armador y banquero herculino había mantenido una relación estrecha con Braña, Abella y Cia en otros ámbitos como los del negocio vidriero, RMA (1851), ff. 58 y ss.

${ }^{67}$ Los hijos de Vila heredaron otro astillero en la Graña, el antiguo dique de Ciarán. Estaba situado en el lugar de la Cabana y fue fundado por Juan Antonio Cardemil en 1810. La casa de Manuel de Ciarán lo compró en 1836, véase Montero (1972: 390-391). Santiago Montenegro y Carmen Fojo vendieron el citado establecimiento, valorado en 25.000 pesetas, a Augusto José de Vila en 1869, AHPC, Manuel Devesa y Gago, leg.10125 (1884), ff. 881 y ss. A su vez, los herederos de Vila lo vendieron a la sociedad J. Pérez Seselle y Cia en 1883, estableciendo en el mismo una fábrica de destilación y refinería de petróleo destinado al alumbrado. Esta fábrica recibió el nombre de La Gallega y estuvo ligada a los intereses financieros de la familia Barrié-Pastor. La sociedad francesa Deutsch y Cia, dedicada al comercio y refinación de los aceites minerales en España, la adquirió en la década de los ochenta por un precio de 230.000 pesetas, AHPC, Manuel Devesa y Gago, leg.10137 (1886), ff. 2873 y ss. Carmona y Nadal (2005: 170) afirman que su vida fue corta dado que en 1900 ya no funcionaba.

${ }^{68}$ Por ejemplo, la corbeta Sofía Matilde, el buque Tula y la fragata española Sofía de Vila, pertenecientes a Augusto José de Vila, fueron construidas en el mismo, AHPC, Manuel Devesa y Gago, leg.10116 (1882), ff. 1196 y ss, Benito María Lores, leg. 9177 (1861), ff. 423 y ss, Ruperto Suárez, leg.9718 (1867), ff. 512 y ss. Asimismo, la casa coruñesa Curbera y Capdesuñer encargó la construcción de la corbeta María en 1877, AHPC, Manuel de la Rosa, leg.9982 (1877), n. ${ }^{\circ} 317$. Brey (1984) contabiliza unos 36 barcos de gran porte construidos en dicho astillero entre 1852 y 1892, la mayoría de madera. 
A la muerte de Augusto José de Vila le sucedieron sus hijos Augusto y Eduardo Vila Algorri ${ }^{69}$. Los primeros años del astillero bajo la hégira de los hermanos Vila fueron difíciles, dado que los conflictos laborales marcaron los inicios de este período. Pero la promulgación de la Ley de Escuadras y las expectativas generadas por la posible demanda estatal de buques animó la formación de una sociedad en 1890. Eduardo y Augusto de Vila revitalizaron las instalaciones asociándose con Juan Fernández Yáñez y López, Pérez y $\mathrm{Cia}^{70}$. Tres años después admitieron como socio industrial al piloto Justo Pastor Fano y López ${ }^{71}$. El ingeniero Andrés Avelino Comerma asumió la dirección técnica y encabezó la marcha del cambio tecnológico necesario para adaptarse a los nuevos tiempos ${ }^{72}$. Así, el astillero estuvo en condiciones de construir buques de tres a cuatro mil toneladas con una plantilla que osciló entre los 450 y los 500 operarios $^{73}$. Este establecimiento construyó una media docena de cañoneras para la Marina en la última década del siglo XIX ${ }^{74}$. A pesar de su carácter privado, su futuro estaba supeditado a los encargos estatales que pudiese obtener. Las expectativas bajo las que se fundó la firma se revelaron irreales y la estrechez de la demanda pronto se hizo notar. Además, tenía competidores no sólo en el extranjero, sino también en la propia península ${ }^{75}$. El destino final de este astillero queda ensombrecido por la falta de datos, aunque sabemos que en 1916 se nombró un liquidador para la sociedad ${ }^{76}$.

El competidor más cercano de Vila y Cia estaba situado en la propia villa de la Graña, el astillero de Otero Gil y Cia, conocido como La Industria Española. Su capital fundacional fue ligeramente inferior al de la sociedad de los hermanos Vila, pero se dedicaron también a la construcción y reparación de vapores de hierro y

\footnotetext{
${ }^{69}$ Augusto José de Vila y León falleció en París el 28 de julio de 1874 y estuvo casado en dos ocasiones. La primera, con Gertrudis Algorri Urioste, con la que tuvo cuatro hijos, Fermina, Dionisia, Augusto y el ingeniero naval Eduardo. Se casó en segundas nupcias con Francisca Fano y Díaz, cuyos hijos Francisco, Eliseo y Gertrudis eran todavía menores de edad en el momento del fallecimiento del patriarca, AHPC, Ruperto Suárez, leg.9745 (1874), ff. 3155 y ss.

${ }^{70}$ Esta sociedad experimentó varios cambios en su razón social. A su disolución se formó Tejero Pérez y Gil, dedicada a la compra-venta de tejidos nacionales y extranjeros, de carbón, las contratas de dichos géneros, la construcción naval, la fabricación de tejidos mediante su participación en $L a$ Galicia Industrial, las comisiones, las consignaciones y el despacho de vapores, RMM (1896) n. ${ }^{\circ} 153$, libro 9, f. 16.

${ }^{71}$ RMM (1890) n. ${ }^{\circ}$ 66, libro 5, f. 17.

72 Penedo (1995).

${ }^{73}$ Se construyó un varadero de 120 metros de eslora, dos gradas y varios almacenes y talleres, véase Penedo (1995).

${ }^{74}$ Penedo (1995).

75 Penedo (1995).

${ }^{76}$ La empresa siguió generando actividad en el Registro Mercantil al menos hasta 1924, RMM (1890) n. ${ }^{\circ} 66$, libro 5, f. 17.
} 
acero y otras embarcaciones. Cuatro individuos aportaron el capital en metálico, herramientas y bienes inmuebles por partes iguales: Nicolás Fuster, José Joaquín Otero, Toribio Gaspar Gil y Juan Cuenca. Sin embargo, la compañía presentó un intenso movimiento en el número de socios derivado de las continuas necesidades financieras. Otero abandonó la sociedad en 1888 y al mismo tiempo se amplió el fondo social en 240.000 pesetas para desarrollar más el astillero y acometer nuevas construcciones y carenas de buques ${ }^{77}$. El nuevo aporte de capital se logró a través de la inclusión del abogado santanderino Joaquín de Vierma y Arostegui, el propietario de Badajoz Luis Pérez de Guzmán y Lasarte y el comerciante ferrolano Enrique Calvo de Castro. Cuatro años más tarde, admitieron un nuevo socio, Bernardo Mac-Costello y Fuentes, que aportó 25.000 pesetas $^{78}$.

Al igual que el astillero del Reverbero, el progreso de la firma se sujetó al Plan de Escuadra de 1887 y la posibilidad de satisfacer parte de los pedidos estatales de buques gracias a la ampliación de las instalaciones. La realidad defraudó también sus expectativas ${ }^{79}$. Algunos contratos a los que aspiraban fueron adjudicados a sus competidores, entre ellos, a los herederos de Augusto José de Vila ${ }^{80}$.

En vísperas de la Primera Guerra Mundial se transformó en sociedad anónima y pasó a denominarse Astillero y Varadero de la Graña S.A. con un capital inferior y dedicándose, además, al comercio de artículos para el aprovisionamiento de los buques ${ }^{81}$. Esta conversión se derivó en gran medida de las dificultades financieras de la compañía. Las pérdidas experimentadas y las deudas obligaron a incorporar a los acreedores de la sociedad como partícipes de la misma. Se entregaron acciones liberadas en pago del haber social y de las deudas contraídas. Entre los acreedores convertidos en socios nos encontramos con Iván Cuenca Romero, Tomás Ayuso Gómez, Nicolás Fuster Romero, Alfredo Moreno y Moscoso de Altamira y la casa

\footnotetext{
${ }^{77}$ Otero recuperó el capital invertido pero autorizó a los demás socios a seguir utilizando sus instalaciones con la condición de que se le abonase una cuarta parte de cada contrato, véase Brey (1992: 34-37).

${ }^{78}$ Mac-Costello sujetó su aportación a la edificación de la capilla de San Andrés en La Graña, RMM (1888) n. ${ }^{\circ}$ 32, libro 3, f. 7.

${ }^{79}$ Brey (1992: 34-37) señala que el Estado se había limitado a encargar «tres modestos cañoneros guardacostas de 18 metros de eslora y el torpedero Ejército de 33,5 metros».

${ }^{80}$ Otero Gil y Cia pleiteó con su rival fundamentando su reclamación en algunas cuestiones formales del contrato social de Vila y Cia. Ésta ganó el pleito pero no antes de ver paralizada su actividad y despedidos sus trabajadores mientras no se producía el fallo del tribunal. El Ayuntamiento de Ferrol ofreció una solución parcial y temporal empleando a algunos de los trabajadores en las obras municipales. Años después, un nuevo conflicto jurídico entre la casa Vila y la Administración se saldó con la incautación gubernamental de las instalaciones y el consiguiente despido de los operarios, véase Brey (1992: 34-37).

${ }^{81}$ RMM (1913) n. ${ }^{\circ}$ 511, libro 19, f. 20.
} 
de banca de Ferrol A. Barreiro y Cia. La sociedad continuó generando actividad en el Registro Mercantil como mínimo hasta 1918 cuando se contabiliza una hipoteca, por lo que asumimos que los problemas no se resolvieron con la transformación social.

La competencia exterior y el encarecimiento de los productos industriales en una región como Galicia que no disponía de plantas siderúrgicas son algunas de las razones que aduce Brey (1992: 34-37) para explicar el fracaso de la construcción naval particular en Ferrol. Pero la reducida demanda apunta como la principal causa del limitado desarrollo de la misma, un fenómeno que también afectaba al Arsenal y que condicionó su desarrollo hasta la primera década del siglo $\mathrm{XX}^{82}$. La demanda privada era también insuficiente. El desarrollo de las compañías de navegación autóctonas fue nulo o en el mejor de los casos reducido. Carmona y Nadal (2005: 153-155) indican que la emigración tuvo efectos nocivos sobre el sector naviero gallego y la construcción naval privada. Los armadores provinciales que habían dominado el tráfico migratorio hacia América en la primera mitad del siglo, se vieron arrinconados más tarde por las navieras extranjeras. Muchos terminarían reconvertidos en consignatarios de las mismas en el lucrativo tráfico migratorio hacia América.

\section{CONCLUSIÓN}

En resumen, la imagen que obtenemos tras el examen de la oferta empresarial del Ferrol decimonónico es la de una villa demasiado vinculada a las necesidades de la Marina y el Estado. La industria privada ferrolana finisecular apenas avanzó. Astilleros como La Industria Española, aserraderos de madera, fábricas textiles y de escabeches representaron el exiguo sector industrial del período 1890-1913. La industria del curtido, en la que la ciudad departamental había sido pionera, apenas avanzó. Quedaron en pie algunas de las tenerías ferrolanas fundadas a finales del siglo XVIII y principios del siglo XIX, pero éstas sobrevivieron en un sector dominado ahora por el cuero compostelano. La composición de las sociedades ferrolanas estuvo cuasimonopolizada por el comercio de ultramarinos, tejidos y vinos.

El menor número de iniciativas en Ferrol frente A Coruña o Compostela restó vigor a su sector empresarial. La acumulación de capital que se produjo quedó muy alejada de la herculina, la líder regional durante el Ochocientos. La crisis agraria

\footnotetext{
${ }^{82}$ Martínez (1896) expresa la opinión de que la competencia naval privada dañó incluso al propio Arsenal de Ferrol.
} 
finisecular coincidió en Ferrol con la frustración de las expectativas generadas por el Plan de Escuadra de 1887, inaugurando un período que podríamos calificar de yermo para la construcción naval tanto pública como privada. A pesar de las inversiones que hubo en ese sector durante los años finiseculares, fue el comercio y no la industria, el que lideró la inversión. El primero se había convertido en la actividad refugio del empresariado ferrolano ante la incertidumbre que rodeaba su primer sector industrial.

El distanciamiento ferrolano se explica tanto por los rasgos internos del entramado empresarial ferrolano como por el mayor dinamismo de los dos principales puertos gallegos, A Coruña y Vigo. En consecuencia, podemos confirmar el languidecimiento de su sector empresarial durante el siglo XIX. El vigor manifestado por otros empresarios de la región a finales del siglo XIX no fue compartido por la economía ferrolana. Las iniciativas industriales fueron muy escasas y el comercio fue el único sector destacado de su estructura empresarial. La dependencia del Arsenal siguió siendo un factor clave para explicar ese retraso. Los datos obtenidos continúan avalando esa hipótesis. Una actividad menos intensa en el Arsenal repercutía invariablemente en el ritmo de creación de sociedades en dicha urbe. La economía ferrolana después de marchitarse durante el Ochocientos no se recuperó demográfica y económicamente hasta la segunda década del siglo XX, cuando la construcción naval entró en una nueva fase expansiva.

\section{APÉNDICE}

\section{Sociedades constituidas en la ciudad de Ferrol, 1820-1914}

(pesetas corrientes)

\begin{tabular}{cllr} 
Fundación & \multicolumn{1}{c}{ Empresa } & \multicolumn{1}{c}{ Objeto social } & Capital \\
\hline 1820 & Lorenzo Bula y Cía & Fábrica de sombreros & 1.830 \\
1821 & Juan Quijano y Cía & Tráfico de vino del país & n.d. \\
1824 & Saubia y Hermana & Panadería, comercio de granos y harinas & 44.768 \\
1827 & Benito Loureiro y Cía & Abasto de carnes & 1.500 \\
1828 & Viuda de Riba y Soler & Fábricas y comercio & n.d. \\
1829 & Gaspar Rico y Cía & Maderas & n.d. \\
1831 & Manuela Méndez y Cía & Comestibles y otras mercancías & 2.000 \\
1831 & Manuela Maceda y Cía & Fábrica de fideos y otras pastas & 1.000 \\
1843 & José García Fernández y Cía & Minería y fundición & 30.000 \\
1843 & Pedro Regueiro y Cía & Compañía de lienzos y otros géneros & 750 \\
1843 & Juana Rodríguez y Cía & Tienda de comestibles & 7.503 \\
1844 & José Adrio y Cía & Tienda de paños y sastrería & n.d. \\
1845 & Carro y Cía & Pesca y salazón de sardina & 22.500 \\
1846 & Garrido Veiga y Cía & Fábrica de lienzos & n.d.
\end{tabular}




$\begin{array}{ll}1850 & \text { Santiago Balado y Cía } \\ 1850 & \text { Casulleras y Guardado } \\ 1851 & \text { José Luis Llopiz y Cía } \\ 1852 & \text { Rufino López y Cía } \\ 1852 & \text { Francisco Rivera y Cía } \\ 1853 & \text { Luis Jober } \\ 1854 & \text { Montero, Aróstegui y Cía } \\ 1862 & \text { Alonso Paris } \\ 1862 & \text { Manuel Barbeito Cedrón y Cía } \\ 1862 & \text { Narciso Pazos y Cía } \\ 1862 & \text { Donapetry y Carro } \\ 1862 & \text { Fernández Hnos } \\ 1863 & \text { Jofre y Linos } \\ 1865 & \text { Maristany Fernández y Cía } \\ 1865 & \text { Rafael Abella Cachón y Cía } \\ 1865 & \text { Modesto Domínguez Pérez y Cía } \\ 1865 & \text { Joaquín Romero Ginzo y Cía } \\ 1868 & \text { Genaro Stoll } \\ 1868 & \text { Eduardo Real López y Cía } \\ 1868 & \text { Manuela Ferrer Piña y Cía } \\ 1870 & \text { Pedro Maristany y Cía } \\ 1871 & \text { La Ley } \\ 1872 & \text { Espinosa Torres y Cía } \\ 1873 & \text { Pradenhes Rodríguez y Cía }\end{array}$

1873 Seselle, Martínez y Cía

1873 Pradenhes, Rodríguez y Stoll

1873 Pedro Martínez y Cía

1874 Carro e Hijos/Carro y Cía

1874 Calvo y Fraga

1874 José Caramelo y Miramontes

1875 Plá, Avizanda y Pradenhes

1875 Vicente Gómez e Hijos

1875 Eduardo Varela y Cía

1875 Rodríguez y Cía

1876 La Amistad

1876 Ogea y Fernández

1877 Llopiz y Hno.

1878 La Honradez

1878 Pedro Meizoso Rodríguez y Cía

1879 Manuel Gómez y Hno.

1880 Sobrino de Seselle Fraga y Cía

1880 Hijos de José Alonso Botas

1880 Carreras e Hijo
Venta de artículos, géneros y comestibles n.d.

Comestibles y géneros coloniales $\quad 15.000$

Negociaciones, arriendos, subarriendos y otros contratos n.d.

Taller de sastrería n.d.

Cantera de pizarra n.d.

Establecimiento de una sastrería $\quad 4.000$

Comercio al por mayor $\quad 60.000$

Comercio de cabotaje $\quad 5.250$

Explotacion de la mina Fojo n.d.

Víveres y bebidas $\quad 21.241$

Tenería n.d.

Casa de comercio n.d.

$\begin{array}{ll}\text { Tenería } & 90.000\end{array}$

Fabricación de tejidos $\quad 61.000$

Venta de efectos de alfarería $\quad 1.375$

Explotación de las patentes para construcciones monolitas 100.000

Adquisición de bienes nacionales n.d.

Venta minorista de géneros del Reino y extranjeros $\quad 50.000$

Peluquería n.d.

Comercio y negocios varios $\quad 40.632$

Fábrica de tejidos, tráfico abacería, líquidos y otros $\quad 138.517$

Comercio de objetos de oro, plata y piedras finas $\quad 50.000$

Venta minorista de géneros nacionales y extranjeros $\quad 115.000$

Comercio de géneros nacionales y extranjeros, comisiones, consignaciones

40.000

Comercio de efectos nacionales, ultramarinos y extranjeros $\quad 67.500$

Suministros al Arsenal de Ferrol n.d.

Salazón de sardina, compra de congrio fresco y curado, otros negocios

n.d.

$\begin{array}{lr}\text { Fábricas de curtidos } & 279.237\end{array}$

Comercio de géneros coloniales, peninsulares y extranjeros $\quad 50.000$

Efectos coloniales $\quad 5.000$

Negociaciones mercantiles $\quad 15.000$

Venta de géneros ultramarinos $\quad 12.500$

Venta por menor de géneros y tejidos de seda, lana, hilo y algodón

20.000

Comercio de artículos de plata y oro n.d.

Fábrica de bebidas gaseosas $\quad 5.284$

Compra y venta de géneros y tejidos de seda, lana y

algodón

54.843

Tráfico de géneros y efectos de comercio, contratas n.d.

Fábrica de bebidas gaseosas, venta de comestibles y vinos $\quad 3.500$

Venta de paños y ropas hechas n.d.

Venta de géneros ultramarinos $\quad 87.500$

Venta al por menor y mayor de efectos nacionales,

ultramarinos y extranjeros

64.500

Comercio de géneros de seda, lana, hilo y algodón

n.d.

Suministro de efectos para el ambigú de algunos

establecimientos 


\begin{tabular}{|c|c|}
\hline 1880 & P. Sobral y Cía \\
\hline 1881 & El Cielo y Nuevo Mundo \\
\hline 1881 & Blanco y García \\
\hline 1881 & Blanco y Carracedo \\
\hline 1881 & Fermín José Zelada y Vilasoa y \\
\hline 1881 & Lorenza Montero e Hijo \\
\hline 1882 & Prieto Puga y Cía \\
\hline 1882 & Vicente Maciñeira González y C \\
\hline 1882 & Juan Zarate y Cía \\
\hline 1882 & Serracant Hermanos y Lago \\
\hline 1883 & González y Martínez \\
\hline 1883 & Juan Martínez Crespo y Cía \\
\hline 1883 & La Guipuzcoana \\
\hline 1884 & Empresa Constructora de un Teat \\
\hline 1884 & José Soto Buela y Cía \\
\hline 1884 & Cooperativa del Ejercito y Armad \\
\hline 1885 & Industria Española \\
\hline 1885 & Hijos de Santos Galán \\
\hline 1885 & Pedro Maristany Maristany y Cía \\
\hline 1885 & Viuda de Francisco Aguilera \\
\hline 1886 & A. Barreiro y Cía \\
\hline 1889 & Castro Rodríguez y Cía \\
\hline 1890 & Vila y Cía \\
\hline 1891 & Marcelino Álvarez y Cía \\
\hline 1891 & La Fuente Muñiz y Cía \\
\hline 1891 & Rotea y Caballo \\
\hline 1892 & Leiceaga y Poublan \\
\hline 1893 & Juan Romero y Cía \\
\hline 1893 & La Equidad \\
\hline 1893 & Álvarez y Martínez \\
\hline 1893 & R. de Avellano y Angueira \\
\hline 1893 & Gallego y Reñones \\
\hline 1894 & La Eléctrica Popular Ferrolana \\
\hline 1894 & García y Castillo \\
\hline 1895 & Eduardo V. Romero y Cía \\
\hline 1897 & Couce y Casademont \\
\hline 1897 & Abizanda y Cía \\
\hline 1897 & Tenreiro y Seijido \\
\hline 1899 & Hijos de Juan A. Dans \\
\hline
\end{tabular}

Tienda de comestibles, vinos y otros artículos

n.d. Comercio de tejidos del reino y extranjeros $\quad 15.000$ Venta y explotación de tejidos $\quad 15.000$

Compra y venta de géneros nacionales y extranjeros $\quad 4.000$

40.000

Comercio al por menor de sedas, tejidos y otros artículos $\quad 7.250$

Venta de hierros, aceros y toda clase de metales ordinarios y artículos de ferretería

50.000

Explotacion de unas lanchas $\quad 16.500$

Explotacion, compra y salazón de pescado n.d.

Fábrica de salazón n.d.

Compra y venta de géneros ultramarinos, nacionales y extranjeros $\quad 30.000$

Explotar una lancha de vapor n.d.

Panadería $\quad 7.875$

$\begin{array}{lr}\text { Construcción de un teatro } & 124.438 \\ \text { Construcción urbana } & \text { n.d. }\end{array}$
Cooperativa
n.d.

Construcción y reparación de vapores de hierro y acero

y otras embarcaciones

200.000

Farmacia y droguería, contratas con el estado o la marina $\quad 122.500$

Tienda de comestibles o abacería $\quad 7.500$

Comercio de quincalla y paquetería $\quad 40.000$

Comercio por mayor de géneros del reino y extranjeros, comisiones y consignaciones

Comercio de muebles y ferretería

70.533

Construcción naval, construcciones metálicas y mixtas, reparaciones

10.000

Comercio al por mayor y menor de géneros ultramarinos, nacionales y extranjeros

378.000

Comercio minorista de géneros de tejidos del reino y extranjero

117.500

Tejidos del reino y extranjeros al por mayor y menor $\quad 60.000$

Ultramarinos, tejidos, contratas de suministro de estos productos

50.000

Ferretería y quincalla al por mayor y menor $\quad 147.500$

Casa de prestamos sobre prendas $\quad 24.595$

Géneros del reino y extranjeros $\quad 20.000$

Joyería y platería $\quad 20.000$

Vinos al por mayor $\quad 10.029$

Alumbrado eléctrico $\quad 250.000$

Tejidos y otros artículos $\quad 15.000$

Ferretería y quincalla al por mayor y menor $\quad 6.000$

Relojería, compra y venta de maquinas de coser, objetos de óptica, culto y mesa

Imprenta, librería, papelería, objetos de escritorio, bazar bisutería $\quad 53.500$

Ultramarinos al por mayor y menor $\quad 34.500$

Comercio al por mayor y menor de géneros ultramarinos y del reino 


$\begin{array}{lllr}1900 & \text { El Oriente } & \text { Explotacion de automóviles a vapor y carruajes } & 126.000 \\ 1901 & \text { Francisco Botas y Cía } & \text { Géneros ultramarinos, del reino y extranjero al por mayor } & \\ & & \text { y menor } & 105.000 \\ 1901 & \text { Ramón Pereira y Cía } & \text { Aserradero de maderas del país a vapor } & 60.000 \\ 1901 & \text { Bernardino González y Vigo } & \text { Géneros ultramarinos y del reino al por menor } & 30.000 \\ 1902 & \text { El Porvenir } & \text { Minas } & 130 \\ 1902 & \text { Souto y Bellón } & \text { Géneros ultramarinos y del reino al por menor } & 30.000 \\ 1902 & \text { Couto y Vidal Romero } & \text { Ferretería y quincalla al por mayor y menor } & 5.000 \\ 1902 & \text { Dopico y Carriles } & \text { Comercio al por mayor y menor de géneros ultramarinos, } & \\ & & \text { extranjeros y del reino } & 130.400 \\ 1903 & \text { Nevotón } & \text { Explotacion de una mina de hierro } & 6.000 \\ 1904 & \text { Novo y Salanova } & \text { Comisiones y representaciones comerciales, seguros } & 850 \\ 1904 & \text { González Buyo y Cía } & \text { Aserradero de madera, molinería de cereales y demás } & \\ & & \text { granos, escabeches de pescados } & 70.000 \\ 1907 & \text { Barcón y Fernández } & \text { Impresión y publicación de dos diarios } & 244.801 \\ 1908 & \text { J. Fernández Grande y Cía } & \text { Comercio al por mayor y menor de géneros de } & \\ & & \text { ultramarinos, harinas, cereales y comisiones } & 15.000 \\ 1909 & \text { Romero Hnos. } & \text { Comercio por mayor y menor de ferretería y demás metales } & 41.600 \\ 1911 & \text { Manuel Calvo Sobrinos y Cía } & \text { Comercio al por menor de géneros ultramarinos } & 20.000 \\ 1912 & \text { Pardo Hnos. } & \text { Venta al por menor de ultramarinos } & 10.000 \\ 1913 & \text { Marcelino Álvarez y Cía } & \text { Comercio al por mayor y menor de géneros ultramarinos, } & \\ & & \text { nacionales y extranjeros } & 175.000 \\ 1914 & \text { Hijas de Nicasio Pérez } & \text { Comercio de madera y materiales de construcción } & 100.000\end{array}$

Fuentes: AHPC, RMA, RMM.

\section{BIBLIOGRAFÍA}

Abreu SERnÁndez, L. F. (2002): Iniciativas Empresariales en Vigo entre 1866 y 1940, Vigo, Servicio de Publicaciones de la Universidad de Vigo.

Álvarez Blázquez, J. M. (1980): «Vigo en el siglo XIX. De la antigua villa a la ciudad moderna», en VV. AA., Vigo en su historia, Vigo, Caja de Ahorros Municipal de Vigo, pp. 357-457.

BARreiro GiL, M. J. (1990): Prosperidade e atraso en Galicia durante o primeiro tercio do século XX, A Coruña, Xunta de Galicia.

BREY, G. (1984): «Construcción naval, obreros y conflictos sociales en El Ferrol a finales del siglo XIX», Estudios de Historia Social n. ${ }^{\circ}$ 3, pp. 79-136.

BREY, G. (1992): «Los Astilleros particulares de la Graña a finales del siglo XIX», Ferrol Análisis n. ${ }^{\circ}$ 3, pp. 34-37.

CARdesín, J. M. (2004): «A tale of two cities: the memory of Ferrol, between the Navy and the working class», Urban History n. ${ }^{\circ} 31$ (3), pp. 329-356.

Carmona BADía, X. (1990): El atraso industrial de Galicia. Auge y liquidación de las manufacturas textiles, 1750-1900, Barcelona, Ariel.

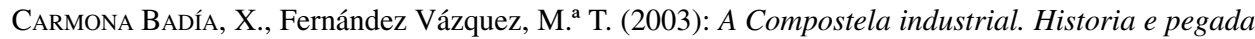
das fábricas de coiros no concello de Santiago, A Coruña, Consorcio de Santiago. 
Carmona, X., Nadal, J. (2005): El empeño industrial de Galicia. 250 años de historia, 1750-2000, A Coruña, Fundación Pedro Barrié de la Maza.

EIRAS RoEl, A. (1988): «Una primera aproximación a la estructura demográfica urbana de Galicia en el Censo de 1787», en R. Villares Paz (coord.), La ciudad y el mundo urbano en la historia de

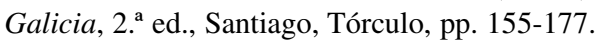

EsCRIGAS, G. (2001): «A fábrica de Xubia, subhastada en 1870», Revista de Neda n. ${ }^{\circ}$ 4, pp. 67-90.

FernándeZ Negral, J. (1991): «Segundo centenario dos reais establecementos de Xuvia. De fábrica de cobrería a centro textil 1791-1991», Cuadernos Ateneo Ferrolan n. ${ }^{\circ}$ 7, pp. 2-96.

Fernández Negral, J. (2002): «Las fábricas de curtidos en la Ría de Ferrol, 1783-1956», Cadernos do Seminario de Sargadelos n. ${ }^{\circ} 90$.

FERnÁNDEZ SANTANDER, C. (1987): 1886-1986. Cámara Oficial de Comercio, Industria y Navegación, A Coruña, COCINC.

Fernández VÁzquez, M. a T. (2002): La industria del curtido en la Galicia contemporánea, Santiago de Compostela, Universidad de Santiago de Compostela, Tesis doctoral.

GonZÁlez LAXE, F. (1984): «La Coruña y su perspectiva histórica pesquera», en Presente y futuro de La Coruña, A Coruña, Instituto José Cornide de Estudios Coruñeses, vol. 2, pp. 97-128.

Juega Puig, S. (1991): El Puerto de A Coruña: Evolución económica: 1962-1985, A Coruña, Diputación provincial.

Lindoso TATo, E. (1999): Empresas y empresarios en La Coruña, 1830-1914, Madrid, Fundación Empresa Pública.

Lindoso TATO, E. (2003): «El Registro Mercantil de A Coruña: una fuente para la historia empresarial decimonónica», en M. Martín, J. Garrues, S. Hernández (dirs.), El Registro Mercantil: una fuente para la historia económica, Granada, Universidad de Granada, pp. 31-51.

Lindoso TATo, E. (2005): El factor empresarial en la Galicia atlántica, 1820-1913, Facultad de Ciencias Económicas y Empresariales de la Universidad de A Coruña, Tesis doctoral.

Lindoso TATo, E. (2006): «Dionisio Tejero, un castellano de Galicia», en X. Carmona (dir.), 25 empresarios galegos, Fundación Galicia-Empresa (en prensa).

López TABoAdA, J. A. (1996): La población de Galicia 1860-1991, Santiago, Fundación Caixa Galicia, vol. 2.

LOZANO COURTIER, A. (1996): «De empresa pública a empresa privada: la gestión de los arsenales del Estado, 1870-1936», en F. Comín y P. Martín (eds.), La empresa en la historia de España, Madrid, Civitas, pp. 369-382.

Lozano Courtier, A. (1997): La moderna construcción naval militar en Galicia: el Arsenal de Ferrol, 1880-1936, Santiago de Compostela, Facultad de Ciencias Económicas e Empresariales, Tesis doctoral.

Lozano Courtier, A. (1999): «A Source of Modest Confort: Las inversiones de Vickers en España, 1897-1936», Revista de Historia Industrial n. ${ }^{\circ}$ 16, pp. 69-89.

MAluquer i Motes, J. (2005): «Consumo y precios» en A. Carreras, X. Tafunell, Estadísticas históricas de España, siglos XIX-XX, Bilbao, Fundación BBVA, vol. III, 2. a edición, pp. 1290-1291. 
Martínez, L. (1896): Provincia de La Coruña. Memoria de Valoraciones para el año de 1893, Madrid, Imp., Fund. y Fab. de Tintas de los Hijos de J. A. García.

Montero Aróstegui, J. (1972): Historia y descripción de El Ferrol, Ferrol, Gersan, reedición de 1859.

NADAL, J. (dir.) (2003): Atlas de la industrialización de España, 1750-2000, Fundación BBVA, Crítica.

Penedo Feijoo, A. (1995): «Estaleiros da Vila da Granha», Ferrol Análisis, pp. 30-35.

Seijoso, M., Malvar, J. (1996): «La imprenta en Ferrol a partir del siglo XIX», Ferrol análisis, pp. 28-61.

Valdivieso Mateo, M. (2000): «A fábrica de luz de A Fervenza», Revista de Neda n. ${ }^{\circ}$ 3, pp. 129-152.

Valdivieso Mateo, M. (2003): «As fábricas de papel do Río Belelle», Revista de Neda n. ${ }^{\circ}$ 6, pp. 8796. 